\title{
The Effects of Mergers with Dynamic Capacity Accumulation
}

\author{
Jiawei Chen \\ Department of Economics, University of California-Irvine*
}

March 2, 2006

\begin{abstract}
We investigate the price and welfare effects of mergers through simulations using a dynamic model of capacity accumulation in which firms produce nearhomogeneous products and compete in prices. We find that mergers are welfarereducing and that their long-run effects are worse than their short-run effects: in the long run average price increases further while total surplus and consumer surplus decrease further. A key feature of the model is that firms are ex ante identical but the industry evolves towards an asymmetric size distribution. If we instead fit the simulated data with an asymmetric costs model, which is a standard approach to explaining persistent asymmetries in market shares, we will systematically underestimate the long-run welfare-reducing effects of mergers, giving rise to misguided antitrust policies.
\end{abstract}

\section{Introduction}

The price and welfare effects of mergers have been the subject of many studies using static models. For example, Salant, Switzer, and Reynolds (1983), Perry and Porter (1985), Farrell and Shapiro (1990), Levin (1990), McAfee and Williams (1992), and Pesendorfer (2003) analyze Cournot mergers, while Deneckere and Davidson (1985), Levy and Reitzes (1992), and Werden and Froeb (1994) focus on Bertrand mergers. However, as suggested by Berry and Pakes (1993), static models do not take into account the long-run reactions of merging and nonmerging firms, so their results can be misleading.

Gowrisankaran (1999), Pesendorfer (2005), and Cheong and Judd (forthcoming) study the price and welfare effects of mergers in dynamic settings. Pesendorfer (2005) and Cheong

*3151 Social Science Plaza, Irvine, CA 92697-5100, jiaweic@uci.edu. I am grateful to Joseph Harrington and Matthew Shum for their encouragement and advice. 
and Judd (forthcoming) explicitly restrict their attention to symmetric premerger industry structures, and the dynamic capacity-constrained Cournot model in Gowrisankaran (1999) also leads to symmetric structures. ${ }^{1}$ These symmetries are not typical given the fact that there are substantial and persistent differences in the sizes of firms in most industries (even some homogeneous or near-homogeneous products industries are highly asymmetric-we will come back to this point later). ${ }^{2}$

In this paper we extend the Besanko and Doraszelski (2004) duopoly model of dynamic capacity accumulation with price competition and product differentiation to more than two firms, and use it to predict both the short-run and the long-run effects of hypothetical mergers in near-homogeneous products industries. The Markov-perfect-equilibrium (MPE) framework described in Ericson and Pakes (1995) is adapted to study the evolution of an oligopolistic industry, and a key feature of the model is that firms are ex ante identical and face the same cost structure but develop persistent differences in their capacities and market shares due to idiosyncratic shocks to their investments and depreciation. Simulations based on the model show that mergers are welfare-reducing and that their long-run effects are worse than their short-run effects: in the long run average price increases further while total surplus and consumer surplus decrease further. The worsening of the merger effects in the long run results from the fact that certain firms in the postmerger industry optimally choose to let their capacities shrink, resulting in higher prices, lower total surplus, and lower consumer surplus.

These predictions are then compared to the ones obtained when we instead fit the simulated data with an asymmetric costs model (firms are ex ante asymmetric by having different but constant marginal costs). The comparison reveals substantial bias: with the asymmetric costs model we will systematically underestimate the long-run welfare-reducing effects of mergers, giving rise to misguided antitrust policies. In particular, a merger that would result in a substantial reduction in total welfare might actually be approved based on total welfare considerations.

The above comparison is meaningful because both the asymmetric capacities model and

\footnotetext{
${ }^{1}$ See Besanko and Doraszelski (2004).

${ }^{2}$ For example, Gort (1963) estimates the correlation between firms' 1947 and 1954 market shares and finds that among the 205 U.S. manufacturing industries examined, 152 had a coefficient of .8 or higher. Mueller (1986) also finds that $44 \%$ of the 350 U.S. manufacturing industries studied never saw their industry leader change over a 22-year period. More recently, Baldwin (1995) shows that for the largest firms in each Canadian manufacturing industry, the predicted duration of tenure in a top rank is quite long: 28, 17, 14, and 12 years for firms ranked 1, 2, 3, and 4, respectively. Geroski and Toker (1996) obtain 17, 10, 11, and 9 years in a similar study on 54 British industries.
} 
the asymmetric costs model can lead to persistent asymmetries in market shares, which are widely observed. The asymmetric costs model is a standard approach to explaining persistent asymmetries in market shares. For example, in their analysis of the price and welfare effects of hypothetical mergers among U.S. long-distance carriers, Werden and Froeb (1994) assume that carriers have constant marginal costs that can be different from each others'.

For industries in which products have different perceived qualities, the persistent asymmetries in market shares can, at least in part, be explained by the differences in perceived qualities; but for industries with homogeneous or near-homogeneous products, such as vitamins, generic drugs, chemicals, and aluminum, quality differences are certainly not a central force and the assumption of cost asymmetries seems even more relevant. However in many homogeneous or near-homogeneous products industries, firms' cost structures are so close and the differences in their market shares are so large and persistent that it would be hardpressed for us to use cost asymmetries to explain the asymmetries in market shares. The US aluminum industry is a case in point. Primary aluminum ingots are highly homogeneous and firms in the industry have similar technology and roughly the same marginal costs. ${ }^{3}$ There are, however, large and persistent differences in firms' market shares. For example, Yang (2002) shows that during the period from 1954 to the early 1980s, the dominant firm Alcoa maintained stable market shares between $30 \%$ and $45 \%$, while no single competitor of Alcoa except for Reynolds and Kaiser had ever obtained a market share greater than $7 \%$. Clearly, these substantial and persistent differences in market shares can not be explained by the small differences in marginal costs and an asymmetric capacities model seems more plausible. $^{4}$

The bias in merger evaluations revealed in this paper results from two differences between the specifications. The first difference is between the asymmetric costs assumption and the asymmetric capacities assumption. The former suggests that a merger could result

\footnotetext{
${ }^{3}$ Rosenbaum (1989) and Yang (2002) argue that primary aluminum ingot is a highly homogeneous product. According to Yang (2002), firms in the industry have roughly equivalent marginal costs because they adopt similar input factors and technology. Froeb and Geweke (1987) also suggest that the dominant firm in the industry has little cost advantage.

${ }^{4}$ There is evidence that capacity constraints are important for the aluminum industry. Reynolds (1986) documents that the average capacity utilization rate for the industry over the period 1951-1970 was 91.9\% and that utilization rates above $100 \%$ were possible because firms had high-cost stand-by capacity. This shows signs of "soft" capacity constraints, i.e., firms can produce beyond their capacity, albeit at much higher costs. Peck (1961) describes the capacity investment behavior of primary aluminum producers and suggests that the competition in the industry led to an "investment race" in the post-1954 period.
} 
in substantial cost savings, while the latter means that there would be little cost savings because firms have little difference in their marginal costs.

The second difference is between a static model and a dynamic model. In the asymmetric costs model, everything is stationary after the merger and the long-run dynamics are not captured. However, in the dynamic model of capacity accumulation, capacities are endogenous and firms will adjust their capacities after the merger, so the long-run effects of a merger can be very different from the short-run effects.

The effects of mergers have been analyzed through simulations in previous studies, but these studies typically focus on the effects immediately after the mergers, and the long-run effects due to postmerger industry dynamics are ignored. See, for example, Werden and Froeb (1994) on mergers of U.S. long distance carriers, Dalkir, Logan, and Masson (2000) on hospital mergers, and Richard (2003) on airline mergers. By using a dynamic model for merger simulations the current study has the advantage that both the short-run and the long-run effects are taken into account.

The organization of this paper is as follows: The next section presents the model. Section 3 examines the price and welfare effects of hypothetical mergers and computes the bias due to the cost misspecification. Section 4 presents robustness checks and some antitrust implications. Section 5 then concludes.

\section{Model}

In this section we extend the Besanko and Doraszelski (2004) duopoly model of dynamic capacity accumulation with price competition and product differentiation to more than two firms producing near-homogeneous products. Some details are the same as those in their paper, for completeness we present them here.

Unlike the Kreps and Scheinkman (1983) model of capacity-constrained price competition with homogeneous products, the Besanko and Doraszelski model with differentiated products can be easily extended from $N=2$ to $N>2$ firms. ${ }^{5}$ Moreover, in the Kreps and Scheinkman model a pure strategy Nash equilibrium does not always exist, making it necessary to consider mixed strategies, which is undesirable when it comes to merger evaluation. In contrast, the Besanko and Doraszelski model assumes that a firm is obliged to satisfy all of its demand and avoids the need to specify a rationing scheme, thus giving rise to a Nash

\footnotetext{
${ }^{5}$ See Boccard and Wauthy (2000) and Deneckere, Doraszelski, and Kovenock (2003) for discussions on the extension of the Kreps and Scheinkman model to $N>2$ firms.
} 
equilibrium in pure strategies in the product market game. ${ }^{6}$ Hence our choice of a model with differentiated products.

Consider $J(J \geq 3)$ firms competing in prices in a discrete-time infinite-horizon setting. We need $J \geq 3$ in order to have an oligopolistic rather than monopolistic industry after hypothetical mergers. In the following development of the model we have $J=3$, and the analysis can be easily extended to models with $J>3$ firms.

\subsection{Demand}

The representative consumer has the following utility function,

$$
u=q_{0}+a_{1} q_{1}+a_{2} q_{2}+a_{3} q_{3}-\frac{b_{1}}{2} q_{1}^{2}-\frac{b_{2}}{2} q_{2}^{2}-\frac{b_{3}}{2} q_{3}^{2}-\gamma_{1} q_{2} q_{3}-\gamma_{2} q_{1} q_{3}-\gamma_{3} q_{1} q_{2},
$$

where $q_{0} \geq 0$ is consumption of the numeraire good, $q_{j} \geq 0, j=1,2,3$, are consumptions of the products of the competing firms, and $a_{j}, b_{j}>0$ and $\gamma_{j} \geq 0, j=1,2,3$, are parameters of the model. Since we are interested in the case in which firms are ex ante identical, we focus on the specification with $a_{1}=a_{2}=a_{3} \equiv a, b_{1}=b_{2}=b_{3} \equiv b$, and $\gamma_{1}=\gamma_{2}=\gamma_{3} \equiv \gamma$ (so that the products are symmetrically differentiated). Furthermore, let $\theta \equiv \frac{\gamma}{b}$, where $\theta \in[0,1)$ measures the degree of product differentiation, ranging from 0 for independent goods to 1 for homogeneous goods. The values of $\theta$ examined in this paper are greater than or equal to 0.9 , representing near-homogeneous goods industries. (1) becomes

$$
u=q_{0}+a q_{1}+a q_{2}+a q_{3}-\frac{b}{2} q_{1}^{2}-\frac{b}{2} q_{2}^{2}-\frac{b}{2} q_{3}^{2}-\theta b q_{2} q_{3}-\theta b q_{1} q_{3}-\theta b q_{1} q_{2} .
$$

Maximizing (2) with respect to $q_{0}, q_{1}, q_{2}$, and $q_{3}$ subject to the budget constraint $q_{0}+p_{1} q_{1}+p_{2} q_{2}+p_{3} q_{3}=y$ yields the following linear inverse demand functions:

$$
p_{j}\left(q_{j}, q_{-j}\right)=a-b q_{j}-\theta b \sum q_{-j}, j=1,2,3
$$

which give us a demand system:

$$
q_{j}\left(p_{j}, p_{-j}\right)=\frac{1}{b\left(1+\theta-2 \theta^{2}\right)}\left[a(1-\theta)-(1+\theta) p_{j}+\theta \sum p_{-j}\right], j=1,2,3,
$$

where $q_{-j}$ and $p_{-j}$ denote the demands and the prices of firm $j$ 's rivals, respectively.

The above specification first appeared in Bowley (1924), and has been picked up by Spence (1976) and Dixit (1979).

\footnotetext{
${ }^{6}$ See, for example, Maggi (1996).
} 


\subsection{States and Transitions}

Firms compete in a dynamic process. In period $t$, firms' capacities are denoted by $\bar{q}_{1 t}, \bar{q}_{2 t}$, and $\bar{q}_{3 t}$, respectively, where $\bar{q}_{j t} \in\left\{\bar{Q}_{1}, \bar{Q}_{2}, \ldots, \bar{Q}_{M}\right\}, 0<\bar{Q}_{1}<\bar{Q}_{2}<\ldots<\bar{Q}_{M}$, and $M$ is the number of possible capacity levels. The state of the industry is $S_{t}=\left(s_{1 t}, s_{2 t}, s_{3 t}\right) \in$ $\{1,2, \ldots, M\}^{3}$, where $s_{j t}$ is firm $j$ 's capacity level in period $t$. In what follows, the time subscripts in $\bar{q}_{j t}, s_{j t}$, and $S_{t}$ are sometimes dropped to make the notation concise.

If firm $j$ has capacity $\bar{q}_{j}$, then its cost function is given by

$$
C\left(q_{j} \mid \bar{q}_{j}\right)=\frac{1}{1+\eta}\left(\frac{q_{j}}{\bar{q}_{j}}\right)^{\eta} q_{j}, j=1,2,3 .
$$

(5) poses a "soft" capacity constraint in the following sense: if $\eta$ is large, then as long as $q_{j}$ is less than $\bar{q}_{j}$, marginal cost $c\left(q_{j} \mid \bar{q}_{j}\right)=\left(\frac{q_{j}}{\bar{q}_{j}}\right)^{\eta}$ is relatively small; but once $q_{j}$ becomes greater than $\bar{q}_{j}$, marginal cost increases rapidly. ${ }^{7}$ Note that $c($.$) does not have firm subscript,$ i.e., different firms have the same cost structure; this preserves the condition that firms are ex ante identical. ${ }^{8}$ It is against this identical cost structure across firms that we later assume firms have different but constant marginal costs, and calculate the bias in merger evaluation due to this misspecification.

Firms also invest to increase their capacities, and the success of their investment is stochastic. The probability that firm $j$ 's investment is successful is increasing in $x_{j} \geq 0$, the amount spent on investment by firm $j$. Formally, if in the current period firm $j$ has capacity $\bar{Q}_{m}, m=1,2, \ldots, M$, and invests $x_{j}$, and there is no depreciation in capacity, then the probability that firm $j$ 's capacity becomes $\bar{Q}_{m+1}$ in the next period is $\frac{\alpha x_{1}}{1+\alpha x_{1}}$, where $\alpha>0$ indexes how likely investments are to be successful. Firms can only increase their capacities "step by step", i.e., a firm's capacity can not jump from $\bar{Q}_{m}$ in the current period to $\bar{Q}_{m+2}$ in the next period.

Unless a firm is operating at the lowest capacity level, its capacity is subject to stochastic depreciation, indexed by the depreciation rate $\delta \geq 0$. Specifically, if there is no investment, then a firm with $\bar{Q}_{m}$ in the current period will have $\bar{Q}_{m-1}$ in the next period with probability $\delta$. A firm's capacity can not jump from $\bar{Q}_{m}$ in the current period to $\bar{Q}_{m-2}$ in the next period.

Taking into account both the investment process and the depreciation process, the tran-

\footnotetext{
${ }^{7}$ The cost specification in Perry and Porter (1985) corresponds to a special case of the soft capacity constraint with $\eta=1$. The specification was later used in some studies on merger effects, e.g., McAfee and Williams (1992) on the welfare implications of Cournot mergers.

${ }^{8}$ Robustness checks in Section 4 show that allowing firms to have slight differences in their cost structures in the capacity model has little impact on our analysis.
} 
sition probabilities for firm $j$ are:

$$
\begin{gathered}
\operatorname{prob}\left(s_{j}+1 \mid s_{j}, x_{j}\right)=\left\{\begin{array}{clc}
\frac{\alpha x_{j}}{1+\alpha x_{j}} & \text { if } & s_{j}=1, \\
\frac{(1-\delta) \alpha x_{j}}{1+\alpha x_{j}} & \text { if } & 2 \leq s_{j} \leq M-1,
\end{array}\right. \\
\operatorname{prob}\left(s_{j} \mid s_{j}, x_{j}\right)=\left\{\begin{array}{clc}
\frac{1}{1+\alpha x_{j}} & \text { if } & s_{j}=1, \\
\frac{1+\delta \alpha x_{j}-\delta}{1+\alpha x_{j}} & \text { if } & 2 \leq s_{j} \leq M-1, \\
\frac{1+\alpha x_{j}-\delta}{1+\alpha x_{j}} & \text { if } & s_{j}=M,
\end{array}\right.
\end{gathered}
$$

and

$$
\operatorname{prob}\left(s_{j}-1 \mid s_{j}, x_{j}\right)=\frac{\delta}{1+\alpha x_{j}} \quad \text { if } \quad 2 \leq s_{j} \leq M
$$

where $\operatorname{prob}\left(s_{j}+1 \mid s_{j}, x_{j}\right)$ denotes the probability that a firm has a capacity level of $s_{j}+1$ in the next period, if its current capacity level is $s_{j}$ and it invests $x_{j} \cdot \operatorname{prob}\left(s_{j} \mid s_{j}, x_{j}\right)$ and $\operatorname{prob}\left(s_{j}-1 \mid s_{j}, x_{j}\right)$ are defined analogously.

\subsection{Price Competition}

In single-period competition, each firm sets price simultaneously and then produces to satisfy demand generated according to the demand system in (4). Firm $j$ 's profit maximization problem is given by:

$$
\max _{p_{j} \geq 0} p_{j} q_{j}\left(p_{j}, p_{-j}\right)-C\left(q_{j}\left(p_{j}, p_{-j}\right) \mid \bar{q}_{j}\right) .
$$

Solving the first order conditions gives the equilibrium prices $p_{j}^{*}\left(\bar{q}_{j}, \bar{q}_{-j}\right)$, where $\bar{q}_{-j}$ denotes the capacities of firm $j$ 's rivals. We solve for the $p_{j}^{*}$ 's numerically and compute the equilibrium profit for firm $j$ according to

$$
\pi_{j}^{*}\left(s_{j}, s_{-j}\right) \equiv \Pi_{j}^{*}\left(\bar{q}_{j}, \bar{q}_{-j}\right)=q_{j}\left(p_{j}^{*}, p_{-j}^{*}\right) p_{j}^{*}-C\left(q_{j}\left(p_{j}^{*}, p_{-j}^{*}\right) \mid \bar{q}_{j}\right) .
$$

\subsection{Policy Function and Value Function}

Let $V_{j}\left(s_{1}, s_{2}, s_{3}\right)$ denote the expected net present value of firm $j$, and let $x_{j}\left(s_{1}, s_{2}, s_{3}\right)$ denote the amount firm $j$ invests in the current period given the state. $V_{j}$ and $x_{j}$ are firm $j$ 's value function and policy function, respectively. We will restrict ourselves to symmetric Markov perfect equilibria (MPE). See Doraszelski and Satterthwaite (2005) for arguments that show the existence of a symmetric MPE in pure investment strategies provided there is an upper bound on investment. While in general uniqueness cannot be guaranteed, our computations show that different starting points and different convergence routes always lead to the same value functions and policy functions. We will focus our attention on 
firm 1 , knowing that because of symmetry, $V_{2}\left(s_{1}, s_{2}, s_{3}\right)=V_{1}\left(s_{2}, s_{1}, s_{3}\right), V_{3}\left(s_{1}, s_{2}, s_{3}\right)=$ $V_{1}\left(s_{3}, s_{1}, s_{2}\right), x_{2}\left(s_{1}, s_{2}, s_{3}\right)=x_{1}\left(s_{2}, s_{1}, s_{3}\right)$, and $x_{3}\left(s_{1}, s_{2}, s_{3}\right)=x_{1}\left(s_{3}, s_{1}, s_{2}\right)$.

\subsection{Solving the Bellman Equation}

The Bellman equation for this problem is

$$
V_{1}\left(s_{1}, s_{2}, s_{3}\right)=\max _{x_{1} \geq 0} \pi_{1}^{*}\left(s_{1}, s_{2}, s_{3}\right)-x_{1}+\beta \sum_{s_{1}^{\prime}=1}^{M} W_{1}\left(s_{1}^{\prime}\right) \operatorname{prob}\left(s_{1}^{\prime} \mid s_{1}, x_{1}\right),
$$

where $0<\beta<1$ is the time discount rate, $s_{1}^{\prime}$ is the capacity level of firm 1 in the next period, and

$$
\begin{aligned}
& W_{1}\left(s_{1}^{\prime}\right)=\sum_{s_{2}^{\prime}=1}^{M} \sum_{s_{3}^{\prime}=1}^{M} V_{1}\left(s_{1}^{\prime}, s_{2}^{\prime}, s_{3}^{\prime}\right) \operatorname{prob}\left(s_{2}^{\prime} \mid s_{2}, x_{2}\left(s_{1}, s_{2}, s_{3}\right)\right) \operatorname{prob}\left(s_{3}^{\prime} \mid s_{3}, x_{3}\left(s_{1}, s_{2}, s_{3}\right)\right) \\
& =\sum_{s_{2}^{\prime}=1}^{M} \sum_{s_{3}^{\prime}=1}^{M} V_{1}\left(s_{1}^{\prime}, s_{2}^{\prime}, s_{3}^{\prime}\right) \operatorname{prob}\left(s_{2}^{\prime} \mid s_{2}, x_{1}\left(s_{2}, s_{1}, s_{3}\right)\right) \operatorname{prob}\left(s_{3}^{\prime} \mid s_{3}, x_{1}\left(s_{3}, s_{1}, s_{2}\right)\right) .{ }^{9}
\end{aligned}
$$

The first order condition (FOC) for an interior solution to (11) is

$$
-1+\beta \sum_{s_{1}^{\prime}=1}^{M} W_{1}\left(s_{1}^{\prime}\right) \frac{\partial \operatorname{prob}\left(s_{1}^{\prime} \mid s_{1}, x_{1}\right)}{\partial x_{1}}=0
$$

Let

$$
\Delta \equiv\left\{\begin{array}{ccc}
\beta \alpha\left[W_{1}\left(s_{1}+1\right)-W_{1}\left(s_{1}\right)\right] & \text { if } & s_{1}=1 \\
\beta \alpha\left[(1-\delta)\left(W_{1}\left(s_{1}+1\right)-W_{1}\left(s_{1}\right)\right)+\delta\left(W_{1}\left(s_{1}\right)-W_{1}\left(s_{1}-1\right)\right)\right] & \text { if } & 2 \leq s_{1} \leq M-1 \\
\beta \alpha \delta\left[W_{1}\left(s_{1}\right)-W_{1}\left(s_{1}-1\right)\right] & \text { if } & s_{1}=M .
\end{array}\right.
$$

The investment strategy of firm 1 is obtained by solving the above FOC:

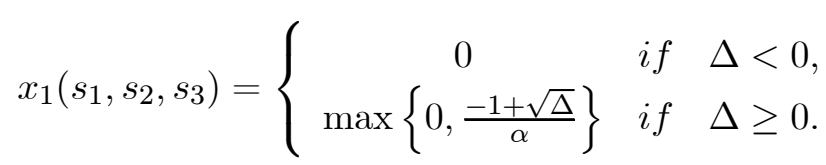

We use Matlab to solve for the value function and the policy function using an iterative algorithm. ${ }^{10}$ The algorithm is a variant of the one developed in Pakes and McGuire (1994) and is illustrated by the flowchart in Figure 1, where $\varepsilon$ is a pre-specified tolerance level and

\footnotetext{
${ }^{9}$ In the Bellman equation the firm always stays in the industry, so the salvage value of capital is not included even though it contributes to the firm's producer surplus.

${ }^{10}$ We thank Ulrich Doraszelski for providing the duopoly programs used in Besanko and Doraszelski (2004).
} 
$\lambda$ indexes how policy functions are updated. In each iteration, we input "old" functions $\left(V^{0}\right.$ and $x^{0}$ ) into the algorithm and obtain "new" functions $(V$ and $x)$. If the old functions and the new functions are different by less than $\varepsilon$, the algorithm stops and the new functions become our solutions; otherwise $V^{0}$ and $x^{0}$ get updated and a new iteration starts.

\subsection{Industry Dynamics and Structure}

We use the following parameter values in our baseline model: $a=4, b=0.1, \alpha=0.0625$, $\beta=\frac{1}{1.05} \simeq 0.952, \delta=0.1, \eta=10, \theta=0.9$, and $M=9$ with $\bar{Q}_{1}=5, \bar{Q}_{2}=10$ up to $\bar{Q}_{9}=45$. So if the industry is in state $\left(s_{1 t}, s_{2 t}, s_{3 t}\right)$, then $\left(\bar{q}_{1 t}, \bar{q}_{2 t}, \bar{q}_{3 t}\right)=\left(5 s_{1 t}, 5 s_{2 t}, 5 s_{3 t}\right)$. Note that the choice of $\alpha$ corresponds to a 0.5 success probability for an investment in the amount of 20 , given the value of $\delta\left(\frac{(1-\delta) \alpha \cdot 20}{1+\alpha \cdot 20}=0.5\right)$. The choice of $\beta$ corresponds to a yearly interest rate of $5 \%$.

Figures $2 \sim 4$ present the equilibrium price function, the equilibrium quantity function, and the single-period profit function, respectively. Each function is illustrated by nine panels with each panel corresponding to one level of the third firm's capacity.

Roughly speaking, the farther away is the industry structure from $(1,1,1)$, the lower the prices are, and prices decrease at a decreasing rate as the structure moves away from this minimal state.

Figure 5 and Figure 6 then present the value function and the policy function, respectively. Notice that firms have no incentive to invest once either of their rivals reaches a capacity level of 5 . In fact, firms engage in a preemption race that is similar to the one in Besanko and Doraszelski (2004): they invest heavily when there is no large firm in the industry, hoping to be the first one to have a high capacity and deter their rivals from investing; but once a rival becomes large, the smaller firms simply give up by investing nothing.

Now we turn to examine the steady-state dynamics of the industry. First, Figure 7 illustrates the closed communicating classes (recurrent sets) of industry states. A closed communicating class is a set of states that can evolve into each other, and once the industry enters one of these states, it will always stay in the set. Number the closed communicating classes from 1 to $K$, where $K$ is the number of such classes. Then put a " $k$ " in Figure 7 for every state that belongs to closed communicating class $k, k=1, \ldots, K$. In our model, $K=1$, i.e., there is only one closed communicating class, $\left\{\left(s_{1}, s_{2}, s_{3}\right) \in\{1,2, \ldots, M\}^{3}\right.$ : $\left.s_{1}, s_{2}, s_{3} \leq 5, s_{1}+s_{2}+s_{3} \leq 13\right\}$. On the outer edge of this set no firm invests. Since there is depreciation, the industry state can remain the same or move inward (i.e., firms have less 
capacities), but can never move outward.

Next, the limiting distribution of the industry is depicted in Figure 8, which shows the probability (fraction of time) that the industry is in each state. Notice that although firms are ex ante identical, in the limiting distribution asymmetric industry structures prevail. In fact, the modes are states $(1,1,5),(1,5,1)$, and $(5,1,1)$, each having a probability of $11 \%$.

Table 1 reports the probabilities of the most likely long-run industry structures, combining the probabilities of the states that differ only by the order of firms. E.g., the probabilities

of states $(1,2,4),(1,4,2),(2,1,4),(2,4,1),(4,1,2)$, and $(4,2,1)$ are combined and assigned to state $(1,2,4)$, the one that has ascending capacities. The industry structures that have combined probabilities greater than $5 \%$ are reported. It is shown that most of the time the industry consists of one large firm and two (equally or unequally) small firms.

Also reported in Table 1 are the corresponding cross-price elasticities. Since firms' products are highly homogenous, one may expect the competition among them to be fierce. It is confirmed by the cross-price elasticities, which range from 1.01 to 8.00 and have a probability-weighted average of 4.07 .

\section{Merger Evaluation}

In this section, we examine the price and welfare effects of hypothetical mergers and compute the bias due to the misspecification described in Section 1. The two specifications used are: (a) firms are ex ante symmetric, and are subject to the same soft capacity constraints in a dynamic setting, and (b) firms are ex ante asymmetric with different but constant marginal costs. Both specifications assume price competition with differentiated products and have the same demand system in (4). As discussed above, both can give rise to persistent asymmetries in market shares.

The procedures are as follows. We first simulate panel data of firms' prices and quantities by letting the model evolve $T=100$ periods according to the first specification (the "true" specification). Call each evolution an experiment. In each experiment, the industry starts with the initial state $(1,1,1)$. Given this state, firms set prices $p_{j}^{*}\left(\bar{q}_{j}, \bar{q}_{-j}\right)$, satisfy their respective demands in (4), and obtain profits generated according to (10). They also invest according to the policy function, and the next industry state is determined stochastically based on the transition probabilities in (6), (7) and (8), taking into account both the investments and the depreciation. A new period arrives with a new state, and the industry moves on. After period $T$ in each experiment two out of the three firms merge, and we compute the price and welfare effects of these hypothetical mergers using both the true 
specification and the alternative specification. We will consider three types of mergers: the largest two firms in terms of output merge (type I mergers), the largest firm merges with the smallest firm (type II mergers), and the smallest two firms merge (type III mergers).

\subsection{The Effects of Mergers with Dynamic Capacity Accumulation}

In our dynamic model of capacity accumulation, premerger output-weighted average price is

$$
\bar{p}=\frac{\sum_{j=1}^{3} q_{j} p_{j}}{\sum_{j=1}^{3} q_{j}} .
$$

Following Spence (1976), we use the following formula for our welfare analysis:

$$
T S=\int_{0}^{q_{1}} p_{1}\left(z_{1}, 0,0\right) d z_{1}+\int_{0}^{q_{2}} p_{2}\left(q_{1}, z_{2}, 0\right) d z_{2}+\int_{0}^{q_{3}} p_{3}\left(q_{1}, q_{2}, z_{3}\right) d z_{3}-T C,
$$

where $T S$ denotes total surplus, $T C$ denotes total costs, and $p_{j}($.$) is given in (3). Note that$

the measure of total surplus is not affected by the order of firms in (17). Under the true specification,

$$
T C=\sum_{j=1}^{3}\left[\frac{1}{1+\eta}\left(\frac{q_{j}}{\bar{q}_{j}}\right)^{\eta} q_{j}\right] .
$$

We then compute

$$
P S=\sum_{j=1}^{3} q_{j} p_{j}-T C,
$$

and

$$
C S=T S-P S
$$

where $P S$ denotes producer surplus and $C S$ denotes consumer surplus. $\bar{p}, T S, T C, P S$, and $C S$ are all computed based on prices, quantities and capacities in period $T$.

Note that investment cost and salvage value of capital do not appear in the expressions of $T S$ or $P S$. Here we are considering the case in which the discounted salvage value of the expected increment in capital due to an investment is equal to the cost of the investment, so they offset each other. ${ }^{11}$ Robustness checks in Section 4 show that our results are not driven by this simplifying condition.

Now we turn to postmerger predictions. For each experiment, we predict price and welfare effects for all three types of mergers.

\footnotetext{
${ }^{11}$ In Reynolds' (1986) welfare analysis of the American aluminum industry using a dynamic capacity model, the salvage value of capital is assumed to equal the cost of its acquisition.
} 
After each hypothetical merger, there are only two firms remaining in the industry. In period $T+1$, the merged firm's capacity is the sum of the capacities of the two merging firms or $\bar{Q}_{M}$, whichever is smaller, while the non-merging firm's capacity remains the same. ${ }^{12}$ From then on, the industry evolves according to the policy function and the transition probabilities for duopoly. For each period after the merger,

$$
T S^{p m}=\int_{0}^{q_{1}^{p m}} p_{1}\left(z_{1}, 0\right) d z_{1}+\int_{0}^{q_{2}^{p m}} p_{2}\left(q_{1}^{p m}, z_{2}\right) d z_{2}-T C^{p m},
$$

where the superscript $p m$ denotes "postmerger", and $p_{j}\left(q_{j}, q_{-j}\right)=a-b q_{j}-\theta b q_{-j}$ is the duopoly inverse demand function. We compute $\bar{p}^{p m}, T S^{p m}$, and $C S^{p m}$ in ways analogous to their premerger counterparts, and calculate their changes $(\Delta \bar{p}, \Delta T S$, and $\Delta C S)$ and percentage changes $(\Delta \bar{p} \%, \Delta T S \%$, and $\Delta C S \%)$ from the premerger values.

Figures $9 \sim 11$ show the predicted changes and percentage changes in average price, total surplus, and consumer surplus, respectively, using the baseline model. All results are averages of 1000 experiments. The solid lines indicate the soft capacity constraints specification (SCC), while the dashed lines indicate the asymmetric costs specification (AC), which will be discussed in the next subsection. In each figure, the left panels depict changes, and the right panels depict percentage changes. From top to bottom, the panels depict changes and percentage changes after type I mergers, type II mergers, and type III mergers, respectively. It is shown that mergers are welfare-reducing and that their long-run effects are worse than their short-run effects.

Short run vs. long run. A feature of the predicted changes and percentage changes under SCC is that they gradually increase in absolute values during the first twenty or thirty periods after the merger, and then relatively stabilize. For example, average price is predicted to increase by about $10 \%$ right after type I mergers, but this number steadily climbs, reaches about $40 \%$ after 25 periods, and then remains there. So under SCC the long-run effects are worse than the short-run effects: average price increases further, while total surplus and consumer surplus decrease further.

The reason lies in the fact that the long-run industry structure is governed by the duopoly ergodic distribution, whereas the short-run structure is merely a result of the merger, and can be incompatible with the ergodic distribution.

\footnotetext{
${ }^{12}$ The additive property of capacity is used in Perry and Porter (1985), Gowrisankaran (1999), and Pesendorfer (2003), among others. In the only closed communicating class of the current model, the constraint of $\bar{Q}_{M}$ is binding only for type I mergers with the following premerger states: $(1,5,5),(2,5,5),(3,5,5)$, $(5,1,5),(5,2,5),(5,3,5),(5,5,1),(5,5,2),(5,5,3)$. These states have a small combined probability of $4.1072 \times 10^{-6}$.
} 
In the period immediately after a type I or type II merger, the industry structure is often "overly asymmetric" in the sense that the merged firm has too large a capacity that the corresponding pair $\left(s_{1}, s_{2}\right)$ is outside of the closed communicating class for the duopoly market. As a result, the merged firm invests nothing and shrinks, so $\left(s_{1}, s_{2}\right)$ eventually falls back into the closed communicating class and never moves out again. In the long run, the industry structure evolves according to the ergodic distribution, and there will be no more "overly asymmetric" industry structure. For example, in our baseline model, the modal industry structure is $(1,1,5)$, so if the industry is at this mode and either a type I merger or a type II merger occurs, the resulting industry structure will be $(1,6)$ in the short run. But $(1,6)$ is outside of the duopoly closed communicating class, and the merged firm shrinks, so the industry structure becomes less asymmetric in the long run.

The gradual extinction of the "overly asymmetric" industry structures is key in understanding the worsening of average price, TS, and CS as time passes. As discussed above, roughly speaking the farther away is the industry structure from the minimal state $(1,1,1)$, the lower the prices are. That is true not only for triopoly markets, but also for duopoly markets, as is shown in Figure 12, which depicts the equilibrium price function for a duopoly market. In the long run, the industry structure is less asymmetric and closer to the minimal state, so the firms charge higher prices.

To see that, again consider the modal industry structure in our baseline model. Prior to any merger, the industry structure $(1,1,5)$ results in prices $(0.98,0.98,0.80)$ and quantities $(4.95,4.95,23.12)$, so the output-weighted average price is 0.85 . After a type I merger or a type II merger, the industry structure becomes $(1,6)$, which gives rise to prices $(1.07,0.86)$ and quantities $(4.99,26.96)$, so the short-run average price is 0.89 , representing a $4.44 \%$ price increase. In the long run, however, the industry structure will be governed by the ergodic distribution. If the market has the duopoly modal structure $(1,5)$ in the long run, prices will be $(1.33,1.14)$ and quantities will be $(5.10,24.05)$, so the average price is further increased to 1.17 , representing a far larger $37.23 \%$ price increase. In the long run, both the small firm and the large firm charge higher prices than in the short run because the industry structure is less asymmetric and closer to the minimal state, resulting in a larger price increase.

On the other hand, if there is a type III merger, the industry structure immediately after the merger will have no firm with the minimal capacity level. But such an industry structure is "unstable" in the sense that the smaller firm or the firm that becomes smaller due to bad shocks will give up by having little or no investment, and will shrink towards having the minimal capacity level. As a result, average price becomes higher in the long 
run since the industry structure becomes closer to the minimal state.

The differences between the short-run and the long-run SCC predictions of TS and CS changes can be explained analogously. To summarize, after a merger of any type certain firms in the industry optimally choose to let their capacities shrink, resulting in higher prices, lower total surplus, and lower consumer surplus, which explains the worsening of the merger effects in the long run.

Differences across types of mergers. The above analysis also sheds light on the differences across types of mergers. Under SCC different types of mergers result in different short-run predicted changes in average price, TS, and CS, but those differences diminish as time passes: in the long run, the predicted changes are almost the same for different types of mergers. That is again due to the fact that in the long run, industry structure, and consequently prices and quantities, are governed by the ergodic distribution. So in the long run, different types of mergers end up with the same distribution of industry structure, and the short-run differences in the predicted changes disappear.

\subsection{Bias in Merger Evaluation due to the Misspecification}

Here we compare the predictions of merger effects in the previous subsection to the ones obtained when we instead fit the simulated data with an asymmetric costs model.

Premerger estimates. Under the asymmetric costs specification (i.e., assuming firms have different but constant marginal costs), premerger output-weighted average price is computed according to (16), same as under the true specification.

To carry out the welfare analysis, we need to estimate $a, b, \theta, c_{1}, c_{2}$ and $c_{3}$, where $c_{j}$ is firm $j$ 's marginal cost, $j=1,2,3$, so we allow the model to have two error terms unobserved by the econometrician:

1. Let $\xi_{j t}$ be the error term on the demand side, so the demand system becomes:

$$
q_{j t}\left(p_{j t}, p_{-j t}\right)=\frac{1}{b\left(1+\theta-2 \theta^{2}\right)}\left[a(1-\theta)-(1+\theta) p_{j t}+\theta \sum p_{-j t}\right]+\xi_{j t}, j=1,2,3,
$$

where $\xi_{j t}$ is $i . i . d$. and $E\left[\xi_{j t} \mid p_{1}, p_{2}, \ldots, p_{T}\right]=0$ with $p_{t}=\left(p_{1 t}, p_{2 t}, p_{3 t}\right) . \xi_{j t}$ is unknown to firm $j$ in period $t$.

2. On the cost side, we have

$$
c_{j t}=\bar{c}_{j}+2 \varepsilon_{j t}
$$


where $\varepsilon_{j t}$ is $i . i . d$. and $E\left[\varepsilon_{j t} \mid p_{-j 1}, p_{-j 2}, \ldots, p_{-j T}\right]=0$. That is, firm $j$ 's marginal cost in period $t$ has two components, a firm-specific component $\bar{c}_{j}$ (firm $j$ 's permanent marginal cost) and a time-varying error term. $\varepsilon_{j t}$ is known to firm $j$ in period $t$, but unknown to other firms.

We then solve the FOCs of the firms' profit maximization problems to obtain

$$
p_{j t}^{*}\left(p_{-j t}, c_{j t}\right)=\frac{(1-\theta) a+\theta \sum p_{-j t}}{2(1+\theta)}+\frac{\bar{c}_{j}}{2}+\varepsilon_{j t}, j=1,2,3 .
$$

Combining (22) and (24), we have a system of six equations, each containing an i.i.d. error term with zero mean. That gives us a system nonlinear panel data model. ${ }^{13} \mathrm{We}$ estimate the six parameters in the system $\left(a, b, \theta, \bar{c}_{1}, \bar{c}_{2}\right.$ and $\left.\bar{c}_{3}\right)$ in Matlab using PNLS (Pooled Nonlinear Least Squares). ${ }^{14}$

$$
\begin{gathered}
\min _{a, b, \theta, \bar{c}_{1}, \bar{c}_{2}, \bar{c}_{3}} \sum_{t=1}^{T}\left(\xi_{1 t}^{2}+\xi_{2 t}^{2}+\xi_{3 t}^{2}+\varepsilon_{1 t}^{2}+\varepsilon_{2 t}^{2}+\varepsilon_{3 t}^{2}\right) \\
\text { s.t. } a>0, b>0,0 \leq \theta<1, \bar{c}_{1} \geq 0, \bar{c}_{2} \geq 0, \text { and } \bar{c}_{3} \geq 0 .
\end{gathered}
$$

After obtaining $\hat{a}, \hat{b}, \hat{\theta}, \widehat{\bar{c}}_{1}, \widehat{\bar{c}}_{2}$ and $\widehat{\bar{c}}_{3}$ as the solution to the above minimization problem, we compute premerger total surplus $(\widehat{T S})$ and premerger consumer surplus $(\widehat{C S})$ using the price and quantity data from period $T$, where the hats in $\widehat{T S}$ and $\widehat{C S}$ indicate that they are computed under the asymmetric costs specification. Note that in this case the premerger total costs are

$$
\widehat{T C}=\sum_{j=1}^{3} \bar{c}_{j} q_{j},
$$

ignoring the mean zero error term.

Postmerger predictions. After each merger, the merged firm's permanent marginal cost is the minimum of the two merging firms', while the non-merging firm's permanent marginal cost remains the same. ${ }^{15}$ Since we have a static model under the asymmetric costs specification and there is no industry evolution, the predictions of merger effects are the same regardless of how many periods have passed since the merger.

\footnotetext{
${ }^{13}$ See Wooldridge (2002) for discussions on nonlinear panel data models.

${ }^{14}$ Under our orthogonality conditions and a mild rank condition the PNLS estimates are consistent. PGLS (Pooled Generalized Least Squares), which uses optimal weighting matrices when computing the sum of squared residuals, gives consistent and efficient estimates. In our case, the differences between PNLS and PGLS estimates are minor.

${ }^{15}$ In Section 4 we consider an alternative case in which the merged firm's permanent marginal cost is the average of the two merging firms'.
} 
Without loss of generality, let the postmerger permanent marginal costs be $\widehat{\bar{c}}_{1}$ and $\widehat{\bar{c}}_{2}$. We will take these two as postmerger marginal costs since the $\varepsilon_{j t}$ 's are unobserved and mean zero. The demand system is

$$
\hat{q}_{j}\left(p_{j}, p_{-j}\right)=\frac{1}{\hat{b}\left(1-\hat{\theta}^{2}\right)}\left[\hat{a}(1-\hat{\theta})-p_{j}+\hat{\theta} p_{-j}\right], j=1,2 .
$$

Solving the FOCs of the firms' profit maximization problems, we have the following postmerger prices:

$$
\hat{p}_{j}^{p m}=\frac{\left(-2+\hat{\theta}+\hat{\theta}^{2}\right) \hat{a}-2 \widehat{\bar{c}}_{j}-\hat{\theta} \hat{\bar{c}}_{-j}}{\hat{\theta}^{2}-4}, j=1,2 .
$$

We drop the time subscripts since these predicted postmerger prices are time-invariant.

Substituting (28) into (27) gives us $\hat{q}_{1}^{p m}$ and $\hat{q}_{2}^{p m}$. We then compute postmerger total surplus according to

$$
\widehat{T S}^{p m}=\int_{0}^{\hat{q}_{1}^{p m}} \hat{p}_{1}\left(z_{1}, 0\right) d z_{1}+\int_{0}^{\hat{q}_{2}^{p m}} \hat{p}_{2}\left(\hat{q}_{1}^{p m}, z_{2}\right) d z_{2}-\widehat{T C}^{p m}
$$

where $\hat{p}_{j}\left(q_{j}, q_{-j}\right)=\hat{a}-\hat{b} q_{j}-\hat{\theta} \hat{b} q_{-j}$ is the duopoly inverse demand function and $\widehat{T C}^{p m}=$ $\sum_{j=1}^{2} \widehat{\bar{c}}_{j} \hat{q}_{j}^{p m}$.

Finally we compute $\widehat{\widehat{p}}^{p m}, \widehat{C S}^{p m}, \Delta \widehat{\bar{p}}, \Delta \widehat{\bar{p}} \%, \Delta \widehat{T S}, \Delta \widehat{T S} \%, \Delta \widehat{C S}$ and $\Delta \widehat{C S} \%$ in ways analogous to their counterparts above. Here we are essentially computing expected average price, expected consumer surplus, etc., due to the existence of the mean zero error terms.

Bias. The dashed lines in Figures 9 11 indicate the asymmetric costs specification $(\mathrm{AC})$. It is shown that under $\mathrm{AC}$, average price is predicted to increase after the mergers, and consumer surplus is predicted to decrease, same as under SCC. The predictions differ in sign when it comes to total surplus, with decreases predicted under SCC and slight increases predicted under AC.

A comparison between the solid lines and the dashed lines in Figures 9 11 reveals that the predictions under AC are substantially biased. Some have a wrong sign, and those with a right sign often miss by a large percentage.

In particular, while under SCC the long-run effects of mergers are worse than the shortrun effects, under $\mathrm{AC}$ the effects are time-invariant. In the cases of average price and consumer surplus, this difference causes the bias to be of opposite signs in the short run versus in the long run. For instance, under SCC consumer surplus is predicted to decrease by $5 \%$ right after a type I merger, and by $15 \%$ after 20 periods. Consequently, the prediction of a $7.5 \%$ decrease under $\mathrm{AC}$ constitutes a $50 \%$ upward bias (in absolute value) right after 
the merger, but a $50 \%$ downward bias in the long run. In the case of total surplus, the predictions under AC miss the point because they are of the wrong sign: after any type of mergers, total surplus is predicted to decrease (by about $1 \%$ to $2 \%$ right after the merger, and about $5 \%$ in the long run) under SCC, but under AC it is predicted to increase (by less than $1 \%)$.

The above bias in merger evaluations results from two differences between the specifications. The first difference is between the asymmetric costs assumption and the asymmetric capacities assumption. The former suggests that a merger could result in substantial cost savings, while the latter means that there would be little cost savings because firms have little difference in their marginal costs. That explains why the $\mathrm{AC}$ specification tends to underestimate the welfare-reducing effects of mergers.

The second difference is between a static model and a dynamic model. In the asymmetric costs model, everything is stationary after the merger and the long-run dynamics are not captured. However, in the dynamic model of capacity accumulation, capacities are endogenous and firms will adjust their capacities after the merger, so the long-run effects of a merger can be very different from the short-run effects. That is the reason why the magnitudes and even the signs of the bias change in the long run.

\section{Robustness Checks and Antitrust Implications}

In this section, we conduct a set of robustness checks by varying the depreciation rate and/or the degree of product differentiation. We also compare the results from several alternative specifications. We then discuss the antitrust implications of our findings.

\subsection{Different Parameter Values}

In order to check whether the results obtained in the previous section are specific to the parameter values we use, we perform a set of robustness checks. Tables $2 \sim 7$ report the results for a range of parameter values. Tables $2 \sim 4$ report short-run bias (immediately after merger), while Tables 5 7 report long-run bias (50 periods after merger). Tables 2 and 5 report type I mergers, Tables 3 and 6 report type II mergers, and Tables 4 and 7 report type III mergers. Each table contains nine sets of parameter values, with $\delta$ being .1, .2 or .3 and $\theta$ being $.9, .95$ or .99 . What we want to examine is how different depreciation rates and/or different degrees of product differentiation affect the results. The tables show that changes in parameter values leave our findings unchanged regarding the price and welfare effects of mergers and the bias due to the misspecification. 
In particular, the following three conclusions are robust to different parameter values.

1. Under SCC mergers are welfare-reducing and their long-run effects are worse than their short-run effects: in the long run average price increases further, while total surplus and consumer surplus decrease further.

2. Compared to SCC, AC leads to overestimation of the increases in average price and the decreases in consumer surplus in the short run, and underestimation of them in the long run.

3. Contrary to the SCC prediction that total surplus decreases after a merger, total surplus is predicted to increase under AC.

\subsection{Alternative Specifications}

As further robustness checks, we compare the long-run results in merger evaluations in four cases.

a. Our baseline case (SCC vs. AC). Each of the following three cases contains one modification to the baseline case.

b. Firms are allowed to have slight differences in their cost structures in the capacity model. To do that, let firm $j$ 's cost function in the SCC specification be given by

$$
C\left(q_{j} \mid \bar{q}_{j}\right)=\left[m c_{j}+\frac{1}{1+\eta}\left(\frac{q_{j}}{\bar{q}_{j}}\right)^{\eta}\right] q_{j}
$$

so that its marginal cost is $c\left(q_{j} \mid \bar{q}_{j}\right)=m c_{j}+\left(\frac{q_{j}}{\bar{q}_{j}}\right)^{\eta}$, where $m c_{j}$ is a firm-specific constant and can be different across firms. The merged firm's $m c$ is the minimum of the merging firms'. Note that in this case we no longer have symmetric and anonymous MPE.

c. Investment costs are deducted from TS and PS in the SCC specification, i.e., the discounted salvage value of the expected increment in capital due to any investment is zero, implying that capital is industry-specific.

d. The merged firm's marginal cost is the average (instead of the minimum) of the merging firms' in the AC specification.

Our findings are robust to these alternative specifications. Table 8 reports the long-run results in merger evaluations in the above four cases for all three types of mergers. For (b), 
the premerger $m c_{j}$ 's used in the capacity model are $(0.5,0.5,0)$, representing an industry in which one firm is more efficient than the other two. ${ }^{16}$ The results in Table 8 show that regardless of the case considered, in the long run the AC specification underestimates increases in average price, decreases in consumer surplus, and decreases in total surplus (or even predict in the opposite direction).

The differences between the results in (a) and (b) are minor, which shows that allowing firms to have slight differences in their cost structures in the capacity model has little impact on our analysis.

The results regarding average price and CS are the same in (a) and (c) since deducting investment costs from TS and PS does not affect average price and CS. The results regarding TS are different but very close, resulting from the fact that in the long run the industry has similar total investments whether there are two firms or three firms. Probability-weighted average of industry total investments is 3.13 in the triopoly model and 3.27 in the duopoly model, where the weights are the probabilities of industry states in the limiting distribution. The difference is only about $4 \%$.

When the merged firm's marginal cost is the average (instead of the minimum) of the merging firms', the AC specification will predict less cost savings resulting from a merger and so the differences between the AC predictions and the SCC predictions are expected to be smaller. That is confirmed by Table 8 . A comparison between (a) and (d) shows that the bias in merger evaluations is smaller in (d), but the directions of the bias are unchanged and the bias is still substantial. Unlike in the baseline case, the AC specification predicts decreases in TS according to (d), but the decreases predicted are noticeably smaller than those predicted in the SCC specification.

\subsection{Antitrust Implications}

Since Williamson (1968), economists have a tradition to base their antitrust analysis regarding mergers on total surplus considerations. In this subsection, we focus on the long-run predicted TS changes under both the SCC specification and the AC specification to explore the antitrust implications.

Our primary interest is the following: if SCC is the true specification, in which direction will the long-run AC predictions be biased?

\footnotetext{
${ }^{16}$ In the baseline capacity model, a firm's marginal cost is 1 if it produces at its full capacity, and 4.05 if it overproduces by $15 \%$.
} 
Define

$$
B \equiv \frac{\Delta \widehat{T S}-\Delta T S}{|\Delta T S|},
$$

where $\Delta \widehat{T S}$ and $\Delta T S$ are long-run predicted changes in TS under AC and SCC, respectively, and $|\Delta T S|$ is the absolute value of $\triangle T S$. $B$ measures the percentage bias of the long-run $\mathrm{AC}$ prediction and bears the sign of the bias.

Figure 13 presents the histograms of $B$ for our baseline model. From top to bottom are the histograms for type I mergers, type II mergers, and type III mergers, respectively. The histograms show that the AC predictions are severely biased upward most of the time: the mode of $B$ is at about 1 , and the values of the percentage bias cluster around the mode, regardless of the type of the mergers. For type I mergers, the AC predictions are greater than the SCC predictions $76.2 \%$ of the time. That number is $73.7 \%$ for type II mergers, and $77.9 \%$ for type III mergers. That means the AC predictions generally underestimate mergers' welfare-reducing effects, or even predict to the opposite.

The reason lies in the fact that the $\mathrm{AC}$ assumption attributes the persistent asymmetries in market shares to the differences in marginal costs and suggests that there would be substantial effects of cost savings resulting from a merger, when in fact there would be little cost savings because firms actually have little difference in their marginal costs-in this case the real source of the persistent asymmetries in market shares is the asymmetric capacities.

Figures 14 and 15 present the histograms of $B$ with $\delta$ changed to 0.2 (Figure 14) or $\theta$ changed to 0.8 (Figure 15). These histograms are qualitatively the same as the ones in Figure 13. Further changes in $\delta$ or $\theta$ or changes in other parameters have minimal effects on the histograms, showing that our conclusions are robust to changes in parameter values.

Our analysis thus shows that if the AC specification is assumed when the true specification is SCC, a merger that would result in a substantial reduction in total welfare might actually be approved based on total welfare considerations.

\section{Conclusion}

In this paper we investigate the price and welfare effects of mergers through simulations using a dynamic model of capacity accumulation in which firms produce near-homogeneous products and compete in prices. A key feature of the model is that firms are ex ante identical and face the same cost structure but develop persistent differences in their capacities and market shares due to idiosyncratic shocks to their investments and depreciation. We find that mergers are welfare-reducing and that their long-run effects are worse than their short- 
run effects: in the long run average price increases further while total surplus and consumer surplus decrease further. The worsening of the merger effects in the long run results from the fact that certain firms in the postmerger industry optimally choose to let their capacities shrink, resulting in higher prices, lower total surplus, and lower consumer surplus.

We then fit the simulated data with an asymmetric costs model (firms are ex ante asymmetric by having different but constant marginal costs), which is a standard approach to explaining persistent asymmetries in market shares. The misspecification results in systematic underestimation of the long-run welfare-reducing effects of mergers, giving rise to misguided antitrust policies. In particular, a merger that would result in a substantial reduction in total welfare might actually be approved based on total welfare considerations.

The above bias in merger evaluation results from two differences between the specifications. The first difference is between the asymmetric costs assumption and the asymmetric capacities assumption. The former suggests that a merger could result in substantial cost savings, while the latter means that there would be little cost savings because firms have little difference in their marginal costs. That explains why the asymmetric costs specification tends to underestimate the welfare-reducing effects of mergers.

The second difference is between a static model and a dynamic model. In the asymmetric costs model, everything is stationary after the merger and the long-run dynamics are not captured. However, in the dynamic model of capacity accumulation, capacities are endogenous and firms will adjust their capacities after the merger, so the long-run effects of a merger can be very different from the short-run effects. That is the reason why the magnitudes and even the signs of the bias change in the long run.

Both the asymmetric costs model and the dynamic model of capacity accumulation can lead to persistent asymmetries in market shares, which are widely observed in various industries, therefore the results in this paper call for future research on methods that can empirically distinguish between the two models.

\section{References}

[1] Baldwin, J. R. (1995). The Dynamics of Industrial Competition, Cambridge University Press, Cambridge, UK.

[2] Berry, S. and A. Pakes (1993). Some Applications and Limitations of Recent Advances in Empirical Industrial Organization: Merger Analysis, American Economic Review 83(2): 247-52. 
[3] Besanko, D. and U. Doraszelski (2004). Capacity Dynamics and Endogenous Asymmetries in Firm Size, RAND Journal of Economics 35(1): 23-49.

[4] Boccard, N. and X. Wauthy (2000). Bertrand Competition and Cournot Outcomes: Further Results, Economics Letters 68: 279-85.

[5] Bowley, A. (1924). The Mathematical Groundwork of Economics, Oxford University Press, Oxford, UK.

[6] Cheong, K.-S. and K. L. Judd (forthcoming). Mergers and Dynamic Oligopoly, Journal of Economic Dynamics and Control forthcoming.

[7] Dalkir, S., J. W. Logan, and R. T. Masson (2000). Mergers in Symmetric and Asymmetric Noncooperative Auction Markets: The Effects on Prices and Efficiency, International Journal of Industrial Organization 18: 383-413.

[8] Deneckere, R. and C. Davidson (1985). Incentives to Form Coalitions with Bertrand Competition, RAND Journal of Economics 16(4): 473-86.

[9] Deneckere, R. J., U. Doraszelski, and D. Kovenock (2003). Bertrand-Edgeworth Triopoly, Working Paper, University of Wisconsin, Madison, WI.

[10] Dixit, A. (1979). A Model of Duopoly Suggesting a Theory of Entry Barriers, Bell Journal of Economics 10(1): 20-32.

[11] Doraszelski, U. and M. Satterthwaite (2005). Foundations of Markov-Perfect Industry Dynamics: Existence, Purification, and Multiplicity, Working Paper, Harvard University, Cambridge, MA.

[12] Ericson, R. and A. Pakes (1995). Markov-Perfect Industry Dynamics: A Framework for Empirical Work, Review of Economic Studies 62: 53-82.

[13] Farrell, J. and C. Shapiro (1990). Horizontal Mergers: An Equilibrium Analysis, American Economic Review 80(1): 107-26.

[14] Froeb, L. and J. Geweke (1987). Long Run Competition in the U.S. Aluminum Industry, International Journal of Industrial Organization 5: 67-78.

[15] Geroski, P. A. and S. Toker (1996). The Turnover of Market Leaders in UK Manufacturing Industry, 1979-86, International Journal of Industrial Organization 14(2): $141-58$. 
[16] Gort, M. (1963). Analysis of Stability and Change in Market Shares, Journal of Political Economy 71: 51-63.

[17] Gowrisankaran, G. (1999). A Dynamic Model of Endogenous Horizontal Mergers, RAND Journal of Economics 30(1): 56-83.

[18] Kreps, D. M. and J. A. Scheinkman (1983). Quantity Precommitment and Bertrand Competition Yield Cournot Outcomes, Bell Journal of Economics 14: 326-37.

[19] Levin, D. (1990). Horizontal Mergers: The 50-Percent Benchmark, American Economic Review 80(5): 1238-45.

[20] Levy, D. T. and J. D. Reitzes (1992). Anticompetitive Effects of Mergers in Markets with Localized Competition, Journal of Law, Economics, and Organization 8(2): 42740.

[21] McAfee, R. P. and M. A. Williams (1992). Horizontal Mergers and Antitrust Policy, Journal of Industrial Economics 40(2): 181-7.

[22] Maggi, G. (1996). Strategic Trade Policies with Endogenous Mode of Competition, American Economic Review 86(1): 237-58.

[23] Mueller, D. (1986). Profits in the Long Run, Cambridge University Press, Cambridge, UK.

[24] Pakes, A. and P. McGuire (1994). Computing Markov-Perfect Nash Equilibria: Numerical Implications of a Dynamic Differentiated-Product Model, RAND Journal of Economics 25: 555-89.

[25] Peck, M. J. (1961). Competition in the Aluminum Industry, Harvard University Press, Cambridge, MA.

[26] Perry, M. and R. Porter (1985). Oligopoly and the Incentive for Horizontal Merger, American Economic Review 75: 219-27.

[27] Pesendorfer, M. (2003). Horizontal Mergers in the Paper Industry, RAND Journal of Economics 34(3): 495-515.

[28] Pesendorfer, M. (2005). Mergers Under Entry, RAND Journal of Economics 36(3): $661-79$. 
[29] Reynolds, S. S. (1986). Strategic Capital Investment in the American Aluminum Industry, Journal of Industrial Economics 34(3): 225-45.

[30] Richard, O. (2003). Flight Frequency and Mergers in Airline Markets, International Journal of Industrial Organization 21: 907-22.

[31] Rosenbaum, D. I. (1989). An Empirical Test of the Effect of Excess Capacity in Price Setting, Capacity-Constrained Supergames, International Journal of Industrial Organization 7: 231-41.

[32] Salant, S. W., S. Switzer, and R. J. Reynolds (1983). Losses from Horizontal Merger: The Effects of an Exogenous Change in Industry Structure on Cournot-Nash Equilibrium, Quarterly Journal of Economics 98(2): 185-99.

[33] Spence, M. (1976). Product Differentiation and Welfare, American Economic Review 66(2): $407-414$.

[34] Werden, G. and L. Froeb (1994). The Effects of Mergers in Differentiated Products Industries: Logit Demand and Merger Policy, The Journal of Law, Economics, \& Organization 10(2): 407-426.

[35] Williamson, O. E. (1968). Economies as an Antitrust Defense: The Welfare Tradeoffs, American Economic Review 58: 18-36.

[36] Wooldridge, J. (2002). Econometric Analysis of Cross Section and Panel Data, The MIT Press, Cambridge, MA and London, UK.

[37] Yang, S. (2002). Identifying a Dominant Firm's Market Power among Sellers of a Homogeneous Product: An Application to Alcoa, Applied Economics 34: 1411-1419. 
Table 1: Most Likely Industry Structures and Corresponding Probabilities and Cross-Price Elasticities

\begin{tabular}{|c|c|cccccc|}
\hline \multirow{2}{*}{$\begin{array}{c}\text { Most Likely } \\
\text { Industry Structures }\end{array}$} & Combined & \multicolumn{6}{|c|}{ Cross-Price Elasticities } \\
\cline { 3 - 7 } & Probabilities & $\mathrm{e}_{\mathrm{i}, \mathrm{j}}$ & $\mathrm{e}_{\mathrm{i}, \mathrm{k}}$ & $\mathrm{e}_{\mathrm{j}, \mathrm{i}}$ & $\mathrm{e}_{\mathrm{j}, \mathrm{k}}$ & $\mathrm{e}_{\mathrm{k}, \mathrm{i}}$ & $\mathrm{e}_{\mathrm{k}, \mathrm{j}}$ \\
\hline$(1,1,5)$ & $33.22 \%$ & 6.3557 & 5.1764 & 6.3557 & 5.1764 & 1.3613 & 1.3613 \\
$(1,2,4)$ & $19.67 \%$ & 5.8368 & 5.2473 & 3.1198 & 2.6623 & 1.6159 & 1.5339 \\
$(1,1,4)$ & $13.74 \%$ & 7.9985 & 7.0796 & 7.9985 & 7.0796 & 2.0728 & 2.0728 \\
$(1,2,5)$ & $11.60 \%$ & 4.5562 & 3.7346 & 2.4797 & 1.9034 & 1.0769 & 1.0084 \\
$(1,2,3)$ & $5.13 \%$ & 7.5780 & 7.2716 & 3.9901 & 3.6763 & 2.6925 & 2.5853 \\
\hline
\end{tabular}

1: The states that differ only by the order of firms are represented by the state that has ascending capacities. E.g., $(1,2,4),(1,4,2),(2,1,4),(2,4,1),(4,1,2)$, and $(4,2,1)$ are represented by $(1,2,4)$. The industry structures that have combined probabilities greater than $5 \%$ are reported.

2: i denotes the smallest firm in terms of capacity, $\mathrm{j}$ the medium, and $\mathrm{k}$ the largest.

$3: e_{i, j}$ denotes the cross-price elasticity of firm i's demand with respect to firm j's price. Other crossprice elasticities are denoted analogously. 
Table 2: Short-Run* Bias in Evaluations of Type I Mergers

\begin{tabular}{|cc|ccc|ccc|ccc|}
\hline$\delta$ & $\theta$ & \multicolumn{2}{|c|}{ Change in Average Price } & \multicolumn{2}{c|}{ Change in Total Surplus } & \multicolumn{3}{c|}{ Change in Consumer Surplus } \\
& & $\mathrm{SCC}^{1}$ & $\mathrm{AC}^{2}$ & $\mathrm{Bis}^{3}{ }^{3}$ & $\mathrm{SCC}$ & $\mathrm{AC}^{2}$ & $\mathrm{Bias}^{3}{ }^{3}$ & $\mathrm{SCC}^{1}$ & $\mathrm{AC}^{2}$ & Bias$^{3}{ }^{3}$ \\
\hline 0.1 & 0.9 & 0.0487 & 0.1322 & $172 \%$ & -1.9723 & 0.1122 & $106 \%$ & -3.0669 & -5.0097 & $-63 \%$ \\
& 0.95 & 0.0080 & 0.0824 & $936 \%$ & -0.7615 & 0.4549 & $160 \%$ & -0.9539 & -3.1132 & $-226 \%$ \\
& 0.99 & 0.0007 & 0.0162 & $2356 \%$ & -0.1289 & 0.4288 & $433 \%$ & -0.1536 & -0.8862 & $-477 \%$ \\
0.2 & 0.9 & 0.0239 & 0.1316 & $450 \%$ & -1.5617 & 0.5425 & $135 \%$ & -1.9922 & -4.7485 & $-138 \%$ \\
& 0.95 & 0.0082 & 0.0950 & $1065 \%$ & -0.6899 & 0.7064 & $202 \%$ & -0.9068 & -3.5876 & $-296 \%$ \\
& 0.99 & 0.0003 & 0.0368 & $11194 \%$ & -0.1222 & 0.6569 & $638 \%$ & -0.1405 & -1.6957 & $-1107 \%$ \\
0.3 & 0.9 & 0.0289 & 0.1401 & $385 \%$ & -1.6020 & 0.7063 & $144 \%$ & -2.2021 & -5.1414 & $-133 \%$ \\
& 0.95 & 0.0118 & 0.1054 & $792 \%$ & -0.7113 & 0.7497 & $205 \%$ & -1.0474 & -3.9531 & $-277 \%$ \\
& 0.99 & 0.0014 & 0.0363 & $2494 \%$ & -0.1239 & 0.7357 & $694 \%$ & -0.1775 & -1.8158 & $-923 \%$ \\
\hline
\end{tabular}

Table 3: Short-Run* Bias in Evaluations of Type II Mergers

\begin{tabular}{|cc|ccc|ccc|ccc|}
\hline$\delta$ & $\theta$ & \multicolumn{2}{|c|}{ Change in Average Price } & \multicolumn{2}{c|}{ Change in Total Surplus } & \multicolumn{3}{c|}{ Change in Consumer Surplus } \\
& & $\mathrm{SCC}^{1}$ & $\mathrm{AC}^{2}$ & $\mathrm{Bias}^{3}$ & $\mathrm{SCC}$ & $\mathrm{SC}^{1}$ & $\mathrm{BC}^{2}{ }^{3}$ & $\mathrm{SCC}^{1}$ & $\mathrm{AC}^{2}$ & Bias $^{3}$ \\
\hline 0.1 & 0.9 & 0.0323 & 0.1253 & $288 \%$ & -1.2917 & 0.3138 & $124 \%$ & -2.0513 & -4.7632 & $-132 \%$ \\
& 0.95 & 0.0043 & 0.0811 & $1775 \%$ & -0.5116 & 0.4833 & $194 \%$ & -0.6195 & -3.0705 & $-396 \%$ \\
& 0.99 & 0.0004 & 0.0157 & $4158 \%$ & -0.0940 & 0.4386 & $567 \%$ & -0.1089 & -0.8722 & $-701 \%$ \\
0.2 & 0.9 & 0.0174 & 0.1308 & $651 \%$ & -1.2432 & 0.5672 & $146 \%$ & -1.5496 & -4.7186 & $-205 \%$ \\
& 0.95 & 0.0052 & 0.0940 & $1713 \%$ & -0.5298 & 0.7317 & $238 \%$ & -0.6678 & -3.5563 & $-433 \%$ \\
& 0.99 & 0.0001 & 0.0368 & $53929 \%$ & -0.0908 & 0.6570 & $823 \%$ & -0.0995 & -1.6948 & $-1603 \%$ \\
0.3 & 0.9 & 0.0203 & 0.1395 & $589 \%$ & -1.2514 & 0.7239 & $158 \%$ & -1.6660 & -5.1212 & $-207 \%$ \\
& 0.95 & 0.0080 & 0.1044 & $1197 \%$ & -0.5463 & 0.7739 & $242 \%$ & -0.7746 & -3.9228 & $-406 \%$ \\
& 0.99 & 0.0009 & 0.0363 & $3883 \%$ & -0.0963 & 0.7358 & $864 \%$ & -0.1318 & -1.8152 & $-1277 \%$ \\
\hline
\end{tabular}

Table 4: Short-Run* Bias in Evaluations of Type III Mergers

\begin{tabular}{|cc|ccc|ccc|ccc|}
\hline$\delta$ & $\theta$ & \multicolumn{2}{|c|}{ Change in Average Price } & \multicolumn{2}{c|}{ Change in Total Surplus } & \multicolumn{2}{c|}{ Change in Consumer Surplus } \\
& & $\mathrm{SCC}^{1}$ & $\mathrm{AC}^{2}$ & $\mathrm{Bias}^{3}$ & $\mathrm{SCC}$ & $\mathrm{AC}^{2}$ & $\mathrm{Bias}^{3}$ & $\mathrm{SCC}^{1}$ & $\mathrm{AC}^{2}$ & Bias$^{3}{ }^{3}$ \\
\hline 0.1 & 0.9 & 0.0223 & 0.1168 & $424 \%$ & -0.5106 & 0.5599 & $210 \%$ & -1.1602 & -4.4623 & $-285 \%$ \\
& 0.95 & 0.0071 & 0.0756 & $960 \%$ & -0.2143 & 0.6282 & $393 \%$ & -0.4334 & -2.8875 & $-566 \%$ \\
& 0.99 & 0.0014 & 0.0148 & $956 \%$ & -0.0354 & 0.4600 & $1399 \%$ & -0.0810 & -0.8406 & $-937 \%$ \\
0.2 & 0.9 & 0.0152 & 0.1223 & $704 \%$ & -0.4171 & 0.8029 & $292 \%$ & -0.8382 & -4.4408 & $-430 \%$ \\
& 0.95 & 0.0074 & 0.0895 & $1113 \%$ & -0.1898 & 0.8467 & $546 \%$ & -0.4217 & -3.4106 & $-709 \%$ \\
& 0.99 & 0.0011 & 0.0358 & $3019 \%$ & -0.0358 & 0.6803 & $1999 \%$ & -0.0749 & -1.6640 & $-2122 \%$ \\
0.3 & 0.9 & 0.0167 & 0.1297 & $678 \%$ & -0.4529 & 1.0090 & $323 \%$ & -0.9301 & -4.8013 & $-416 \%$ \\
& 0.95 & 0.0088 & 0.0996 & $1027 \%$ & -0.1953 & 0.9010 & $561 \%$ & -0.4784 & -3.7668 & $-687 \%$ \\
& 0.99 & 0.0016 & 0.0354 & $2105 \%$ & -0.0343 & 0.7587 & $2311 \%$ & -0.0893 & -1.7846 & $-1899 \%$ \\
\hline
\end{tabular}

*: Immediately after merger.

1: Assuming soft capacity constraints and using true parameter values.

2: Assuming asymmetric costs and using estimated parameter values.

3: $\mathrm{Bias} \%=(\mathrm{AC}-\mathrm{SCC}) / \mathrm{ISCCl} * 100 \%$. 
Table 5: Long-Run* Bias in Evaluations of Type I Mergers

\begin{tabular}{|cc|ccc|ccc|ccc|}
\hline$\delta$ & $\theta$ & \multicolumn{2}{|c|}{ Change in Average Price } & \multicolumn{2}{c|}{ Change in Total Surplus } & \multicolumn{3}{c|}{ Change in Consumer Surplus } \\
& & $\mathrm{SCC}^{1}$ & $\mathrm{AC}^{2}$ & $\mathrm{Bia}^{3}{ }^{3}$ & $\mathrm{SCC}$ & $\mathrm{SC}^{2}$ & $\mathrm{Bias}^{3}$ & $\mathrm{SCC}^{1}$ & $\mathrm{AC}^{2}$ & Bias$^{3}{ }^{3}$ \\
\hline 0.1 & 0.9 & 0.2503 & 0.1322 & $-47 \%$ & -4.2489 & 0.1122 & $103 \%$ & -8.4506 & -5.0097 & $41 \%$ \\
& 0.95 & 0.1710 & 0.0824 & $-52 \%$ & -2.7472 & 0.4549 & $117 \%$ & -5.6301 & -3.1132 & $45 \%$ \\
& 0.99 & 0.1158 & 0.0162 & $-86 \%$ & -1.5624 & 0.4288 & $127 \%$ & -3.4650 & -0.8862 & $74 \%$ \\
0.2 & 0.9 & 0.2275 & 0.1316 & $-42 \%$ & -4.2398 & 0.5425 & $113 \%$ & -7.3877 & -4.7485 & $36 \%$ \\
& 0.95 & 0.2599 & 0.0950 & $-63 \%$ & -4.0550 & 0.7064 & $117 \%$ & -7.9132 & -3.5876 & $55 \%$ \\
& 0.99 & 0.1965 & 0.0368 & $-81 \%$ & -2.8146 & 0.6569 & $123 \%$ & -5.5548 & -1.6957 & $69 \%$ \\
0.3 & 0.9 & 0.1590 & 0.1401 & $-12 \%$ & -3.2859 & 0.7063 & $121 \%$ & -5.5300 & -5.1414 & $7 \%$ \\
& 0.95 & 0.2815 & 0.1054 & $-63 \%$ & -4.2644 & 0.7497 & $118 \%$ & -8.5611 & -3.9531 & $54 \%$ \\
& 0.99 & 0.2901 & 0.0363 & $-87 \%$ & -3.9017 & 0.7357 & $119 \%$ & -8.3896 & -1.8158 & $78 \%$ \\
\hline
\end{tabular}

Table 6: Long-Run* Bias in Evaluations of Type II Mergers

\begin{tabular}{|cc|ccc|ccc|ccc|}
\hline$\delta$ & $\theta$ & \multicolumn{2}{|c|}{ Change in Average Price } & \multicolumn{2}{c|}{ Change in Total Surplus } & \multicolumn{3}{c|}{ Change in Consumer Surplus } \\
& & $\mathrm{SCC}^{1}$ & $\mathrm{AC}^{2}$ & $\mathrm{Bias}^{3}$ & $\mathrm{SCC}$ & $\mathrm{AC}^{2}$ & $\mathrm{Bias}^{3}{ }^{3}$ & $\mathrm{SCC}^{1}$ & $\mathrm{AC}^{2}$ & Bias $^{3}$ \\
\hline 0.1 & 0.9 & 0.2129 & 0.1253 & $-41 \%$ & -3.6534 & 0.3138 & $109 \%$ & -7.3015 & -4.7632 & $35 \%$ \\
& 0.95 & 0.1374 & 0.0811 & $-41 \%$ & -2.3138 & 0.4833 & $121 \%$ & -4.5720 & -3.0705 & $33 \%$ \\
& 0.99 & 0.1296 & 0.0157 & $-88 \%$ & -1.7338 & 0.4386 & $125 \%$ & -3.8718 & -0.8722 & $77 \%$ \\
0.2 & 0.9 & 0.2321 & 0.1308 & $-44 \%$ & -4.3461 & 0.5672 & $113 \%$ & -7.4824 & -4.7186 & $37 \%$ \\
& 0.95 & 0.2507 & 0.0940 & $-62 \%$ & -3.9178 & 0.7317 & $119 \%$ & -7.7145 & -3.5563 & $54 \%$ \\
& 0.99 & 0.1964 & 0.0368 & $-81 \%$ & -2.7784 & 0.6570 & $124 \%$ & -5.6008 & -1.6948 & $70 \%$ \\
0.3 & 0.9 & 0.1684 & 0.1395 & $-17 \%$ & -3.4153 & 0.7239 & $121 \%$ & -5.8532 & -5.1212 & $13 \%$ \\
& 0.95 & 0.2878 & 0.1044 & $-64 \%$ & -4.4074 & 0.7739 & $118 \%$ & -8.6858 & -3.9228 & $55 \%$ \\
& 0.99 & 0.3020 & 0.0363 & $-88 \%$ & -4.0221 & 0.7358 & $118 \%$ & -8.7691 & -1.8152 & $79 \%$ \\
\hline
\end{tabular}

Table 7: Long-Run* Bias in Evaluations of Type III Mergers

\begin{tabular}{|cc|ccc|ccc|ccc|}
\hline$\delta$ & $\theta$ & \multicolumn{2}{|c|}{ Change in Average Price } & \multicolumn{2}{c|}{ Change in Total Surplus } & \multicolumn{2}{c|}{ Change in Consumer Surplus } \\
& & $\mathrm{SCC}^{1}$ & $\mathrm{AC}^{2}$ & $\mathrm{Bias}^{3}$ & $\mathrm{SCC}^{1}$ & $\mathrm{AC}^{2}$ & $\mathrm{Bias}^{3}{ }^{3}$ & $\mathrm{SCC}^{1}$ & $\mathrm{AC}^{2}$ & Bias $^{3}{ }^{3}$ \\
\hline 0.1 & 0.9 & 0.2192 & 0.1168 & $-47 \%$ & -3.7524 & 0.5599 & $115 \%$ & -7.5395 & -4.4623 & $41 \%$ \\
& 0.95 & 0.1210 & 0.0756 & $-38 \%$ & -2.0668 & 0.6282 & $130 \%$ & -4.0852 & -2.8875 & $29 \%$ \\
& 0.99 & 0.1065 & 0.0148 & $-86 \%$ & -1.4873 & 0.4600 & $131 \%$ & -3.1305 & -0.8406 & $73 \%$ \\
0.2 & 0.9 & 0.2231 & 0.1223 & $-45 \%$ & -4.1964 & 0.8029 & $119 \%$ & -7.1620 & -4.4408 & $38 \%$ \\
& 0.95 & 0.2542 & 0.0895 & $-65 \%$ & -3.9588 & 0.8467 & $121 \%$ & -7.8137 & -3.4106 & $56 \%$ \\
& 0.99 & 0.2241 & 0.0358 & $-84 \%$ & -3.2336 & 0.6803 & $121 \%$ & -6.2743 & -1.6640 & $73 \%$ \\
0.3 & 0.9 & 0.1865 & 0.1297 & $-30 \%$ & -3.7107 & 1.0090 & $127 \%$ & -6.3236 & -4.8013 & $24 \%$ \\
& 0.95 & 0.2968 & 0.0996 & $-66 \%$ & -4.5474 & 0.9010 & $120 \%$ & -8.9225 & -3.7668 & $58 \%$ \\
& 0.99 & 0.2863 & 0.0354 & $-88 \%$ & -3.8352 & 0.7587 & $120 \%$ & -8.2951 & -1.7846 & $78 \%$ \\
\hline
\end{tabular}

*: 50 periods after merger.

1: Assuming soft capacity constraints and using true parameter values.

2: Assuming asymmetric costs and using estimated parameter values.

3: $\mathrm{Bias} \%=(\mathrm{AC}-\mathrm{SCC}) / \mathrm{ISCCl} * 100 \%$. 
Table 8: Long-Run* Bias in Merger Evaluations - Alternative Specifications

\begin{tabular}{|cc|ccc|ccc|ccc|}
\hline & Type & \multicolumn{2}{|c|}{ Change in Average Price } & \multicolumn{2}{c|}{ Change in Total Surplus } & \multicolumn{2}{c|}{ Change in Consumer Surplus } \\
& & $\mathrm{SCC}^{1}$ & $\mathrm{AC}^{2}$ & Bias$^{3}{ }^{3}$ & $\mathrm{SCC}^{1}$ & $\mathrm{AC}^{2}$ & Bias$^{3}{ }^{3}$ & $\mathrm{SCC}^{1}$ & $\mathrm{AC}^{2}$ & Bias $^{3}$ \\
\hline a & I & 0.2503 & 0.1322 & $-47 \%$ & -4.2489 & 0.1122 & $103 \%$ & -8.4506 & -5.0097 & $41 \%$ \\
& II & 0.2129 & 0.1253 & $-41 \%$ & -3.6534 & 0.3138 & $109 \%$ & -7.3015 & -4.7632 & $35 \%$ \\
& III & 0.2192 & 0.1168 & $-47 \%$ & -3.7524 & 0.5599 & $115 \%$ & -7.5395 & -4.4623 & $41 \%$ \\
b & I & 0.2381 & 0.1249 & $-48 \%$ & -2.9108 & 0.2009 & $107 \%$ & -6.7635 & -4.0776 & $40 \%$ \\
& II & 0.2179 & 0.1235 & $-43 \%$ & -2.5040 & 0.2328 & $109 \%$ & -6.3252 & -4.0366 & $36 \%$ \\
& III & 0.2239 & 0.1205 & $-46 \%$ & -2.7061 & 0.2993 & $111 \%$ & -6.4122 & -3.9467 & $38 \%$ \\
c & I & 0.2503 & 0.1322 & $-47 \%$ & -4.0871 & 0.1122 & $103 \%$ & -8.4506 & -5.0097 & $41 \%$ \\
& II & 0.2129 & 0.1253 & $-41 \%$ & -3.2325 & 0.3138 & $110 \%$ & -7.3015 & -4.7632 & $35 \%$ \\
& III & 0.2192 & 0.1168 & $-47 \%$ & -3.2073 & 0.5599 & $117 \%$ & -7.5395 & -4.4623 & $41 \%$ \\
d & I & 0.2503 & 0.2015 & $-20 \%$ & -4.2489 & -2.8740 & $32 \%$ & -8.4506 & -6.9842 & $17 \%$ \\
& II & 0.2129 & 0.1934 & $-9 \%$ & -3.6534 & -2.5814 & $29 \%$ & -7.3015 & -6.7272 & $8 \%$ \\
& III & 0.2192 & 0.1377 & $-37 \%$ & -3.7524 & -0.1895 & $95 \%$ & -7.5395 & -5.1406 & $32 \%$ \\
\hline
\end{tabular}

*: 50 periods after merger.

1: Assuming soft capacity constraints and using true parameter values.

2: Assuming asymmetric costs and using estimated parameter values.

3: $\mathrm{Bias} \%=(\mathrm{AC}-\mathrm{SCC}) / \mathrm{ISCCl} * 100 \%$.

a: Baseline case.

b: Firms have different marginal costs in the SCC specification.

c: Investment costs are excluded from TS and PS in the SCC specification.

$\mathrm{d}$ : The merged firm's marginal cost is the average of the merging firms' in the AC specification. 


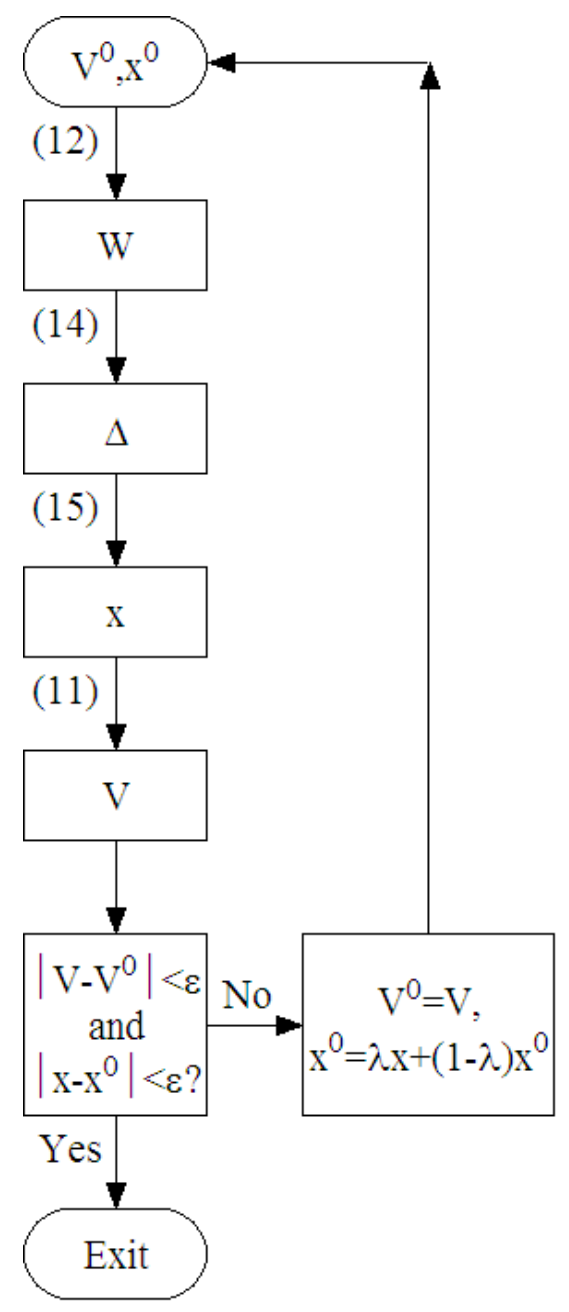

Figure 1: Algorithm flowchart. 

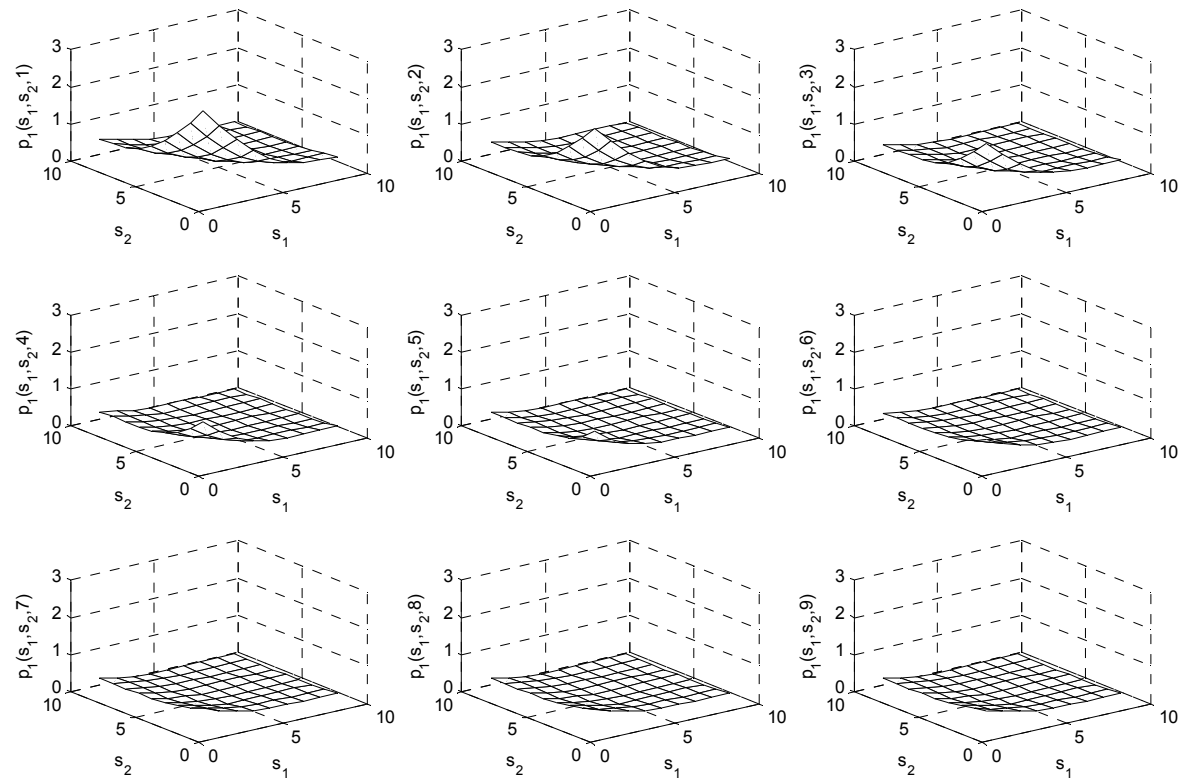

Figure 2: Equilibrium price function (baseline model).
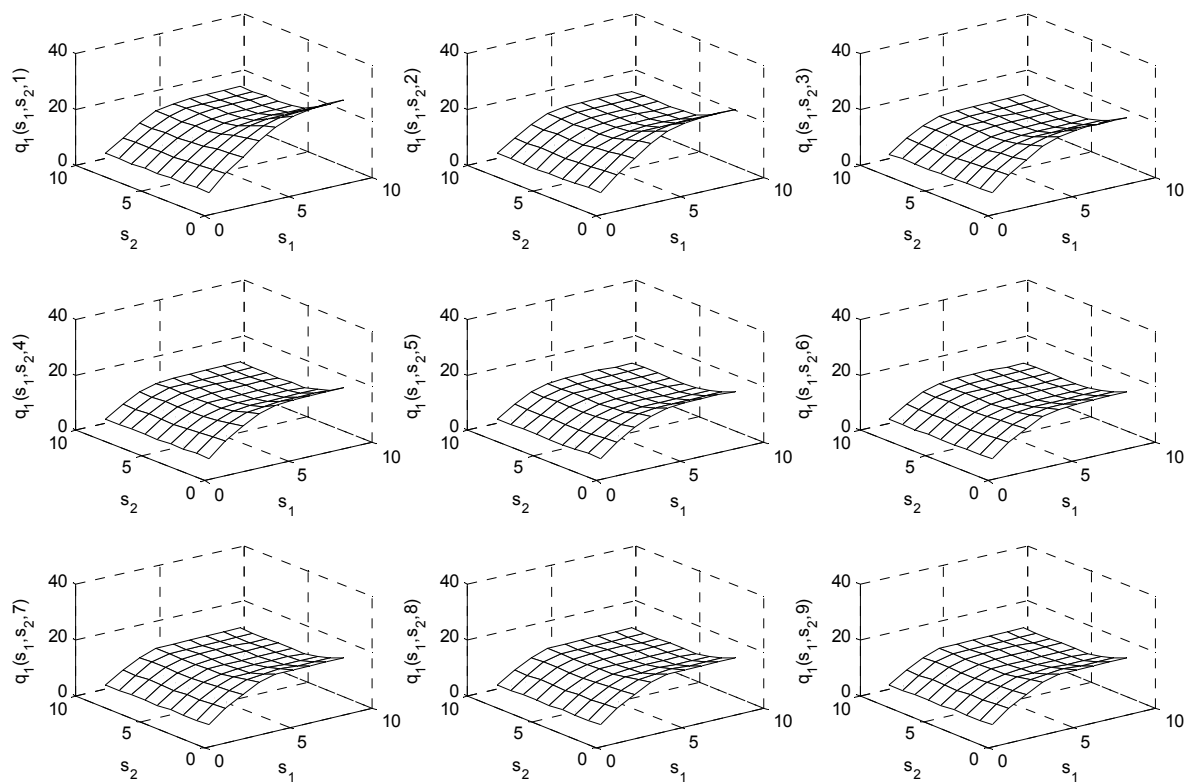

Figure 3: Equilibrium quantity function (baseline model). 

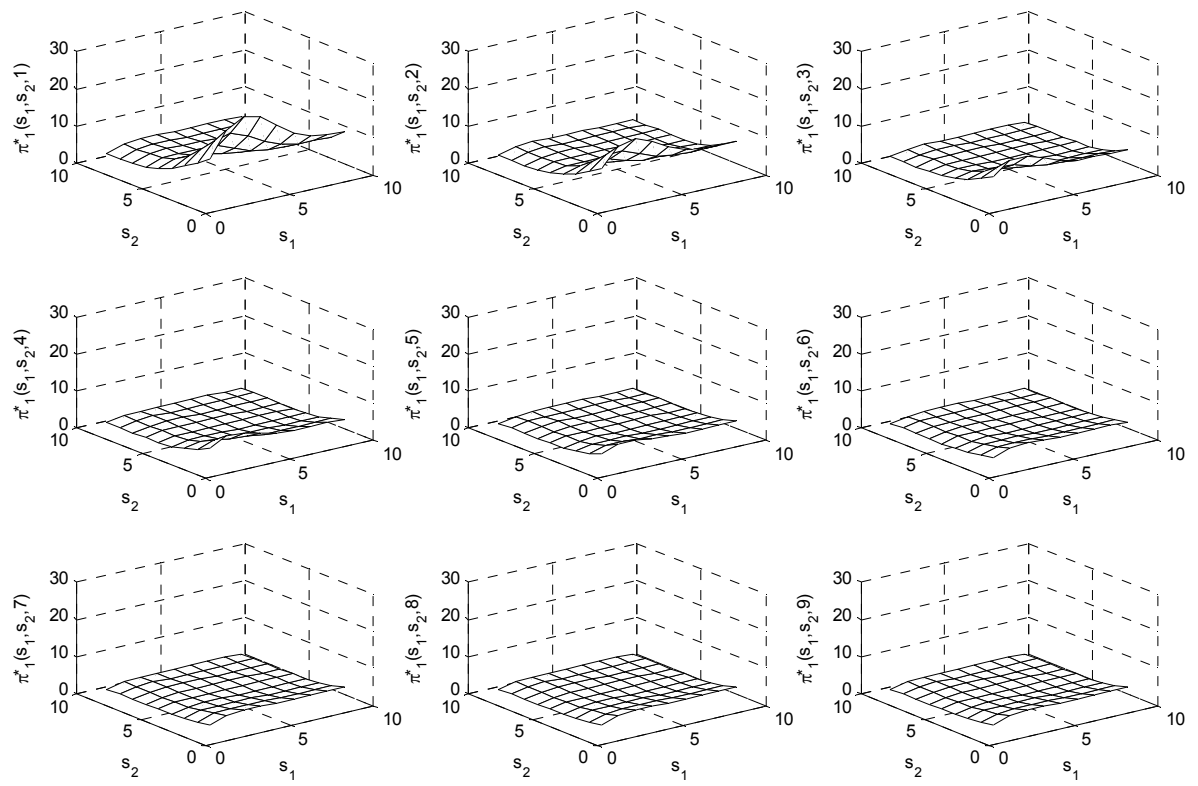

Figure 4: Single-period profit function (baseline model).
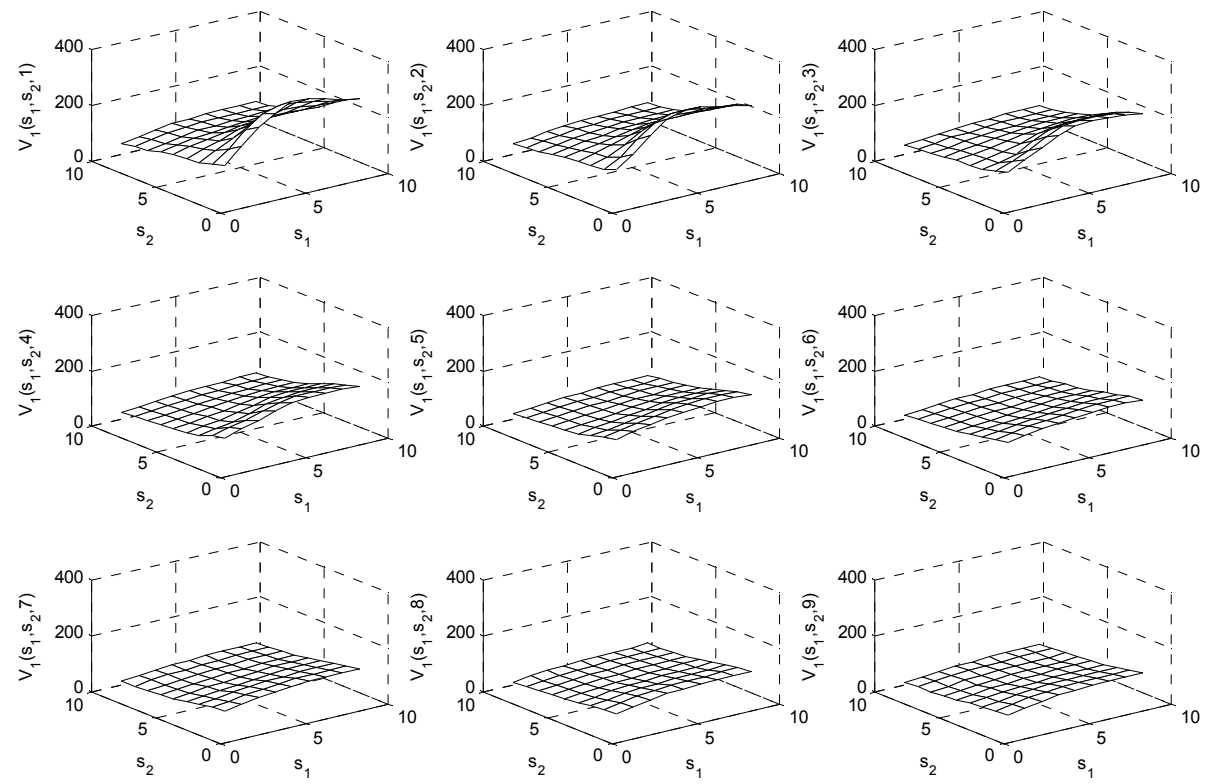

Figure 5: Value function (baseline model). 

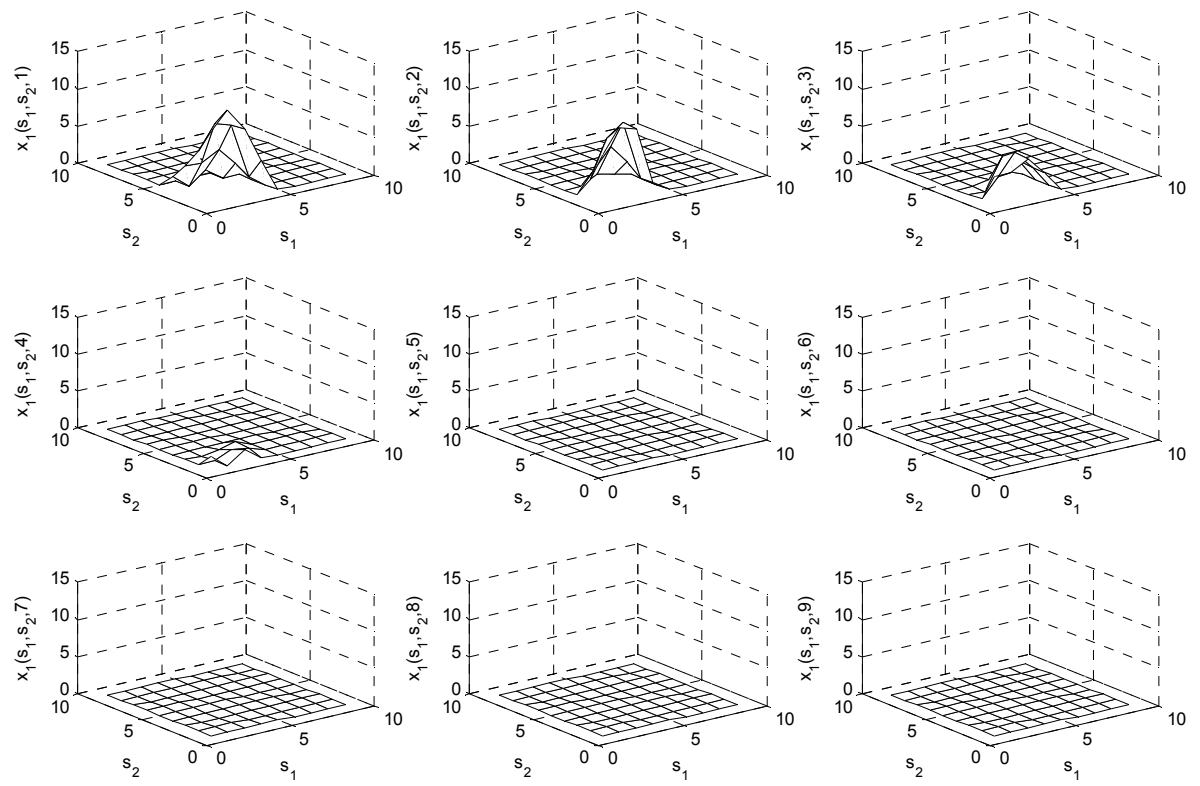

Figure 6: Policy function (baseline model).
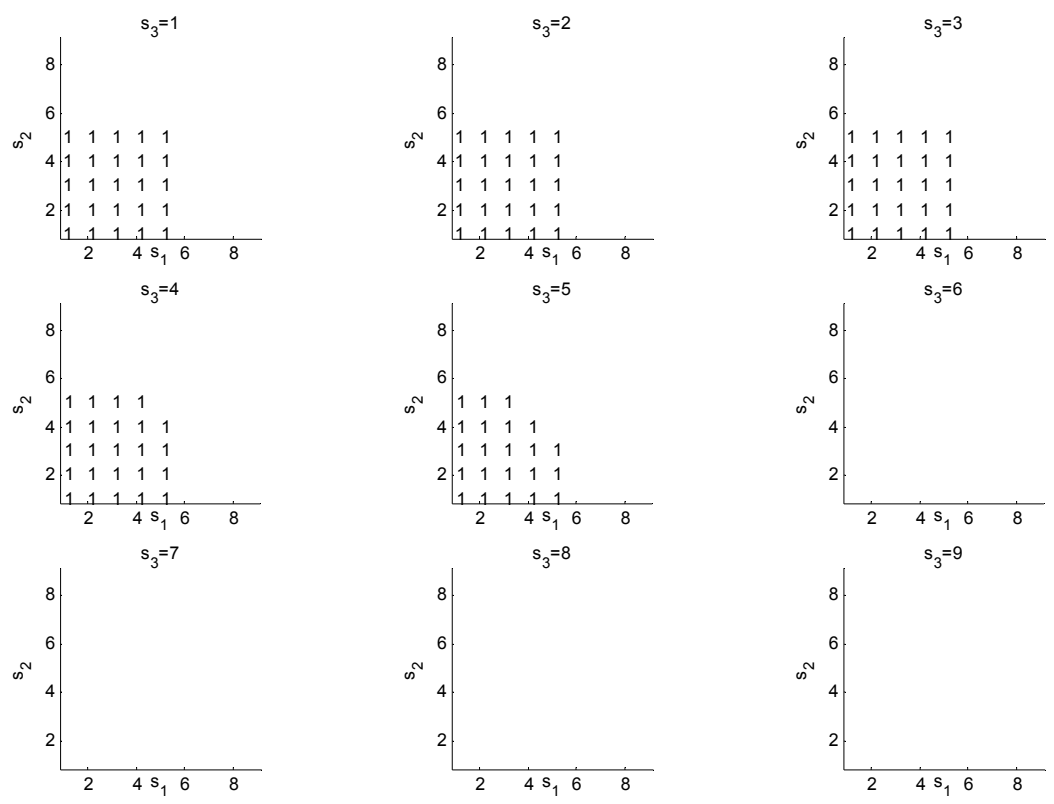

Figure 7: Closed communicating class(es) (baseline model). 

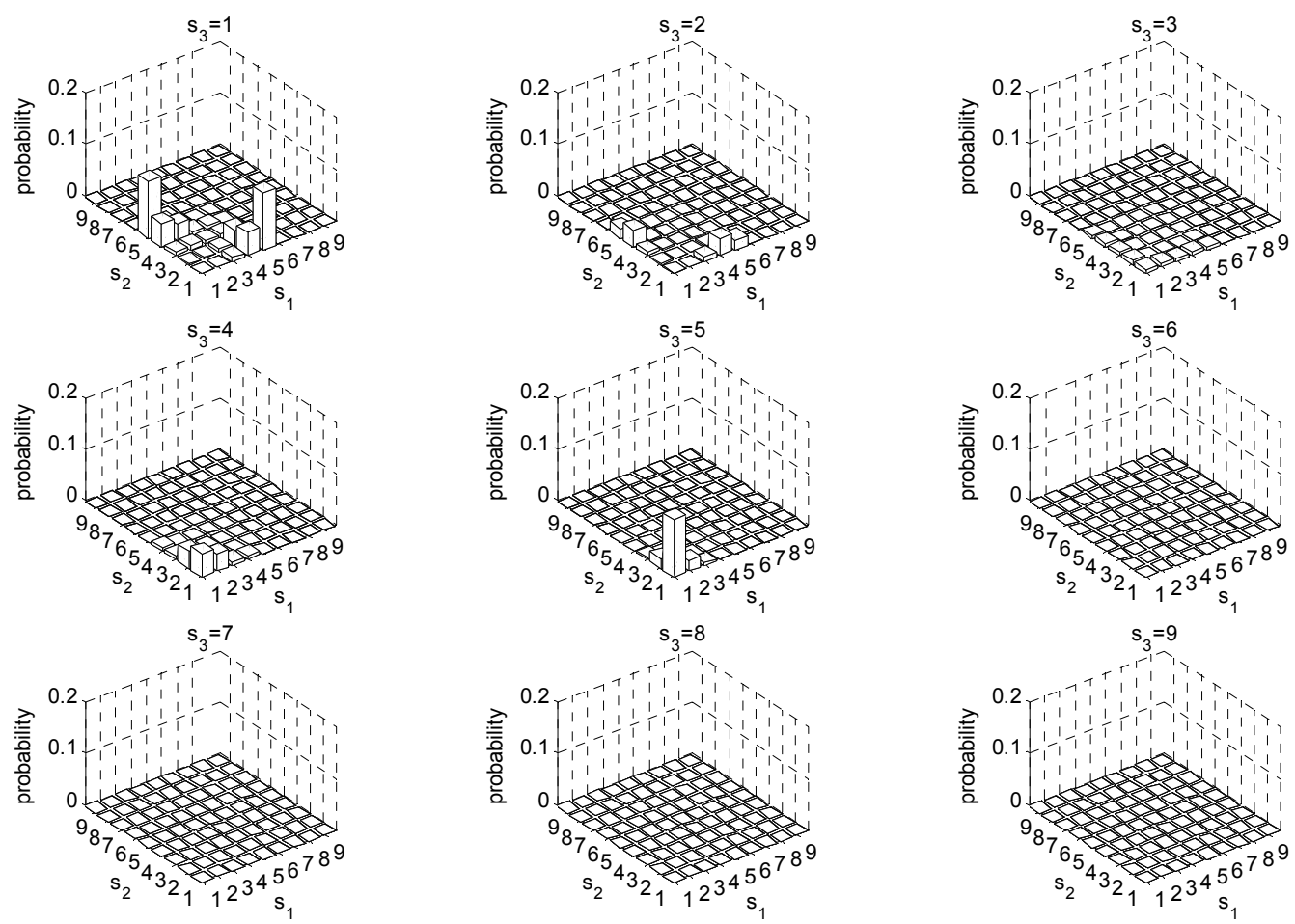

Figure 8: Limiting distribution (baseline model). 

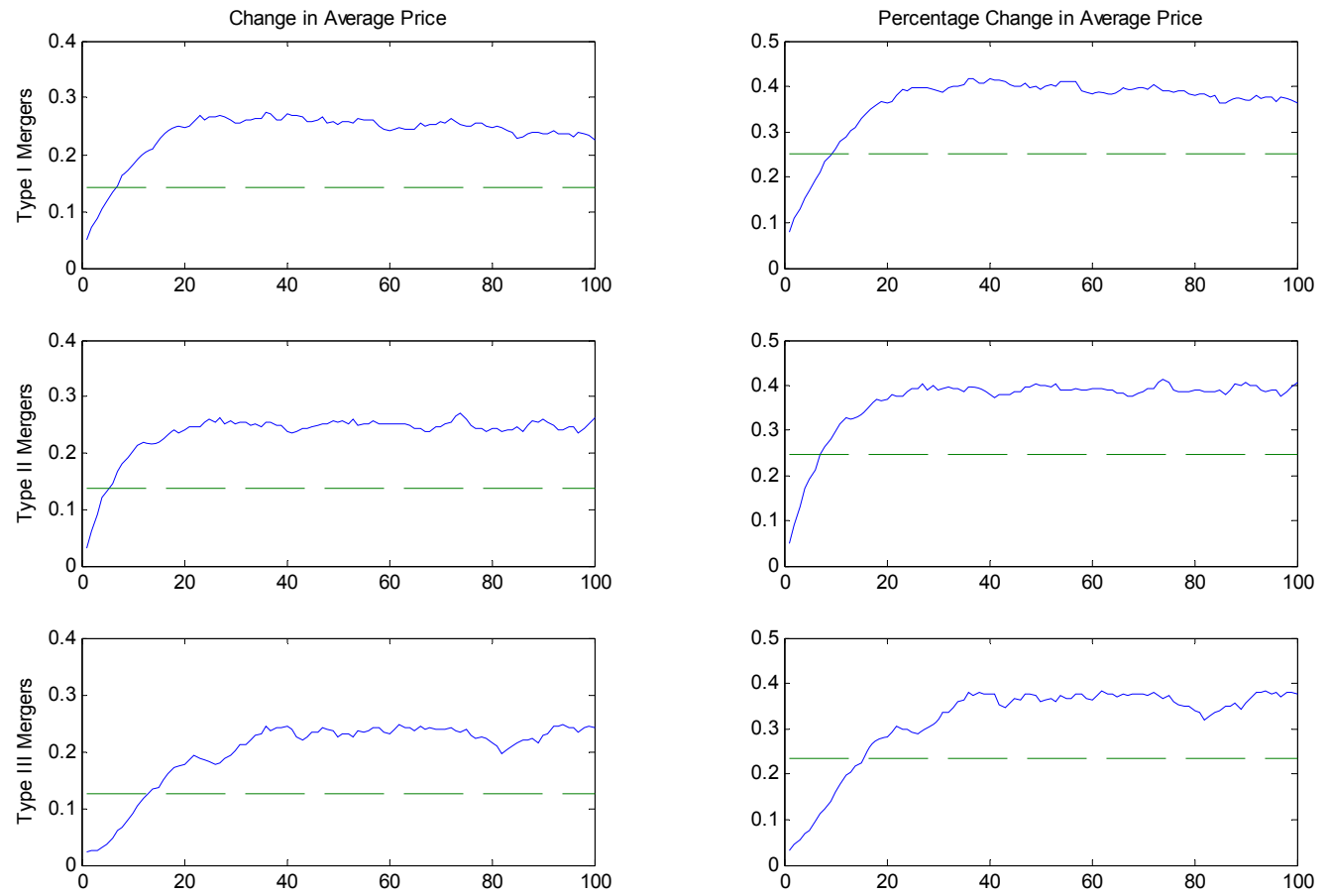

Figure 9: Change and percentage change in average price. Percentage change equals change divided by premerger average price. For example, 0.2 in the right panels means a $20 \%$ increase in average price. Solid lines indicate soft capacity constraints specification, while dashed lines indicate asymmetric costs specification. The horizontal axis shows the number of periods since the merger. There are three types of mergers: the largest two firms in terms of output merge (type I mergers), the largest firm merges with the smallest firm (type II mergers), and the smallest two firms merge (type III mergers). 

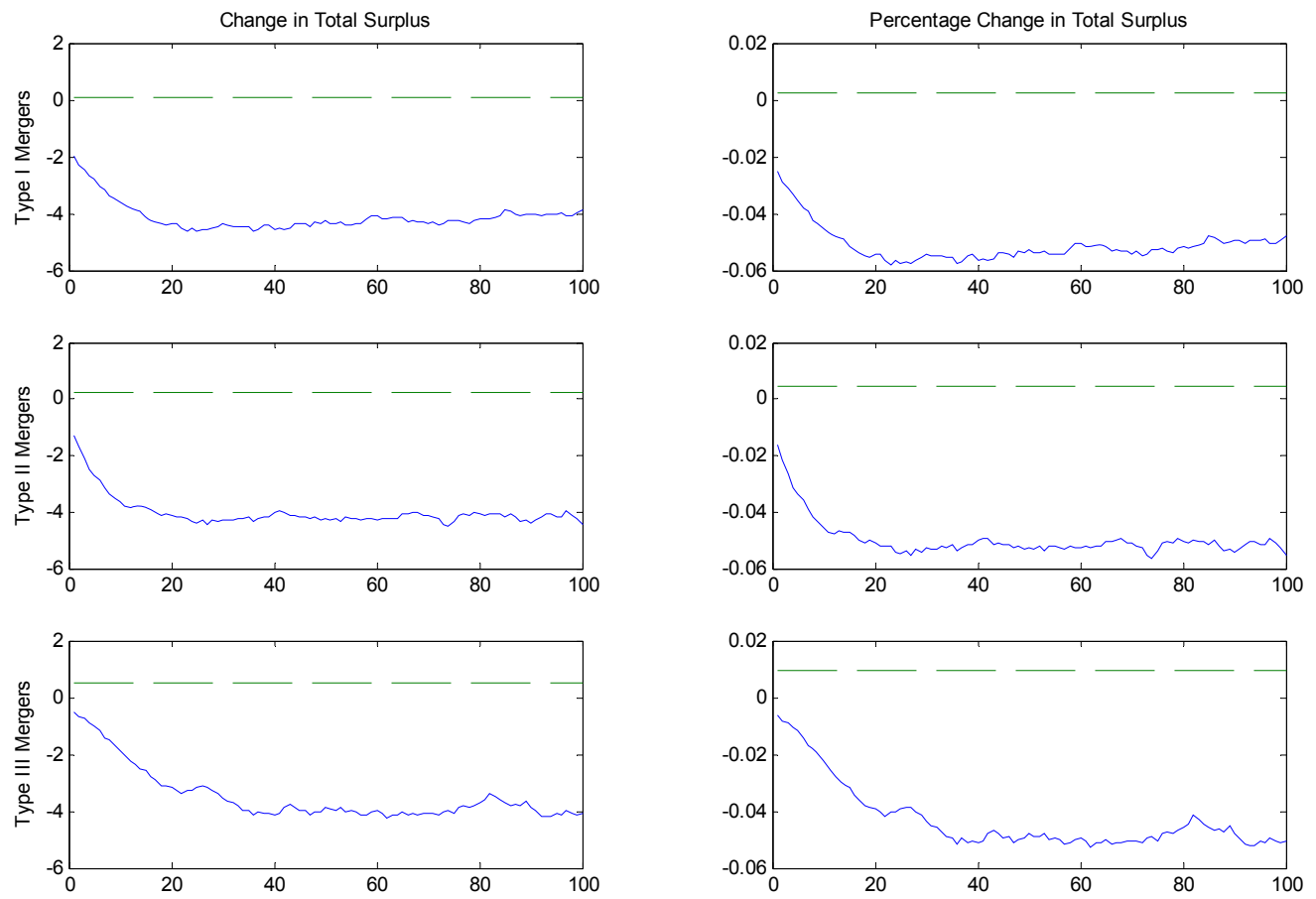

Figure 10: Change and percentage change in total surplus. Percentage change equals change divided by premerger total surplus. For example, -0.02 in the right panels means a $2 \%$ decrease in total surplus. Solid lines indicate soft capacity constraints specification, while dashed lines indicate asymmetric costs specification. The horizontal axis shows the number of periods since the merger. There are three types of mergers: the largest two firms in terms of output merge (type I mergers), the largest firm merges with the smallest firm (type II mergers), and the smallest two firms merge (type III mergers). 

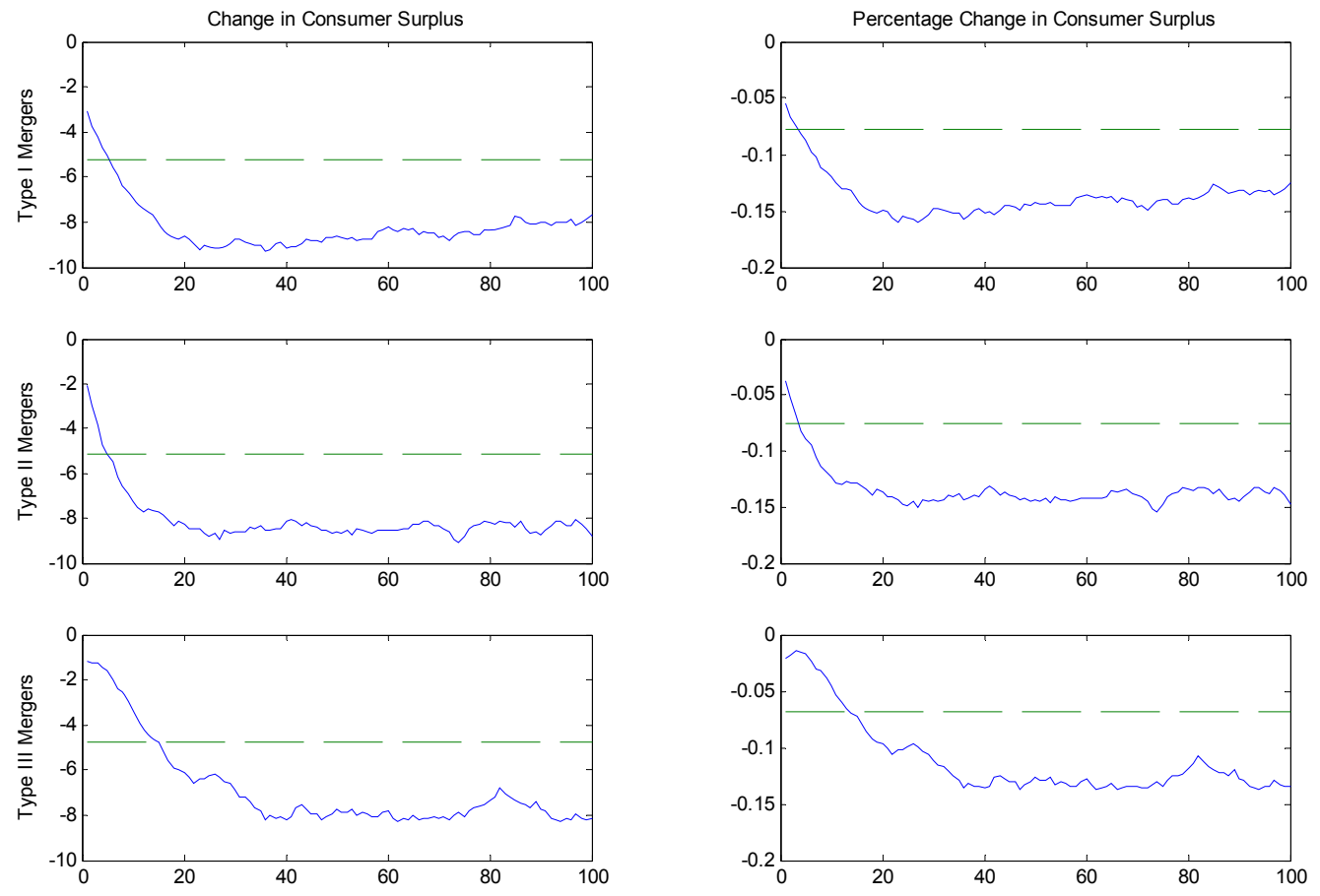

Figure 11: Change and percentage change in consumer surplus. Percentage change equals change divided by premerger consumer surplus. For example, -0.05 in the right panels means a 5\% decrease in consumer surplus. Solid lines indicate soft capacity constraints specification, while dashed lines indicate asymmetric costs specification. The horizontal axis shows the number of periods since the merger. There are three types of mergers: the largest two firms in terms of output merge (type I mergers), the largest firm merges with the smallest firm (type II mergers), and the smallest two firms merge (type III mergers). 


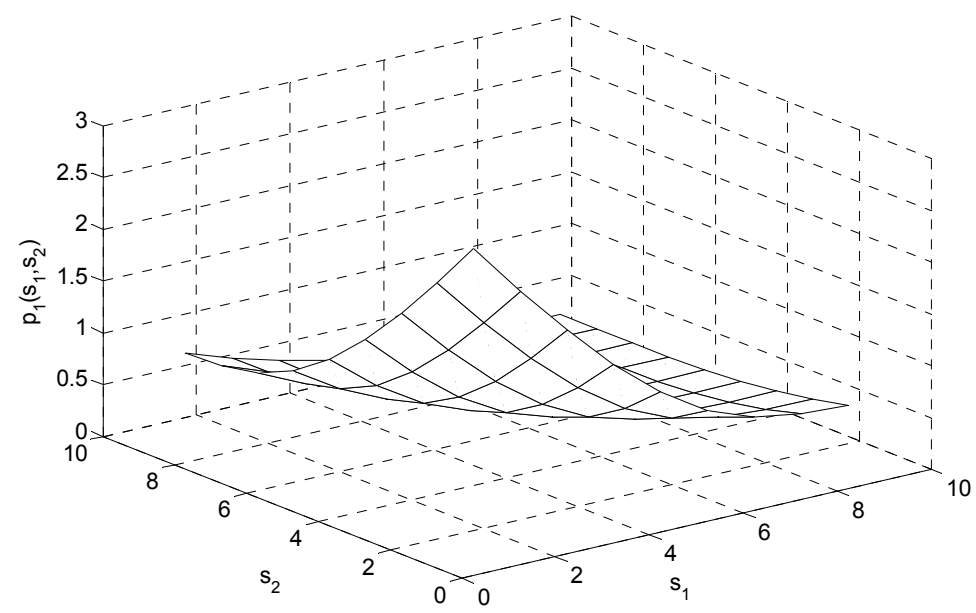

Figure 12: Equilibrium price function: duopoly (baseline model with $J$ changed to 2).
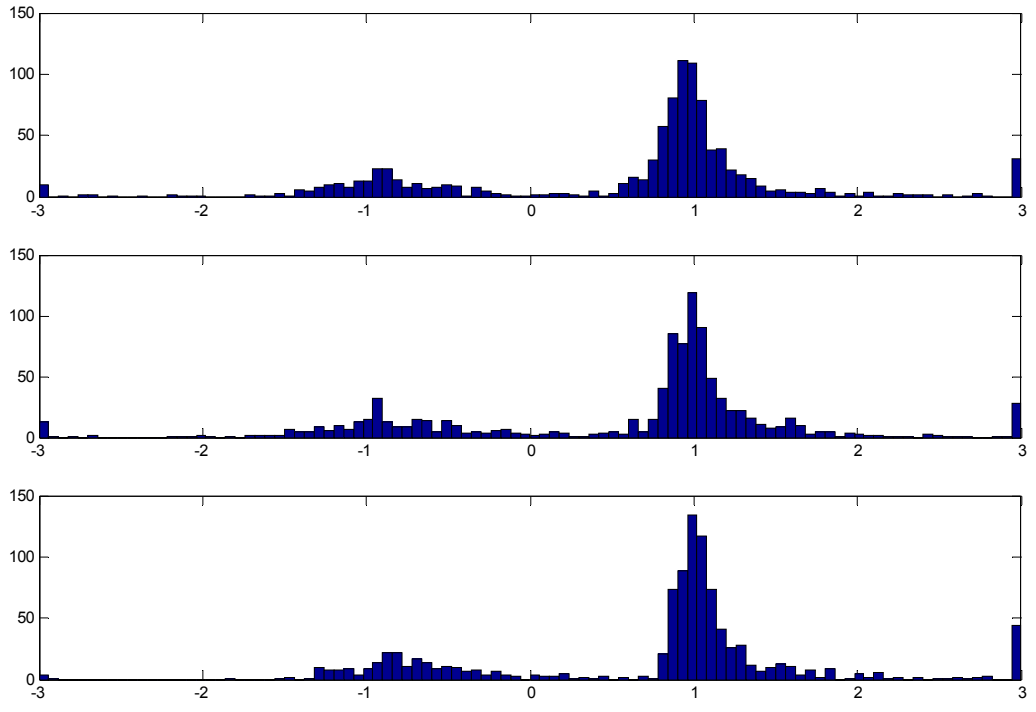

Figure 13: Histograms of $B$ for the baseline model. From top to bottom: type I mergers, type II mergers, and type III mergers. 

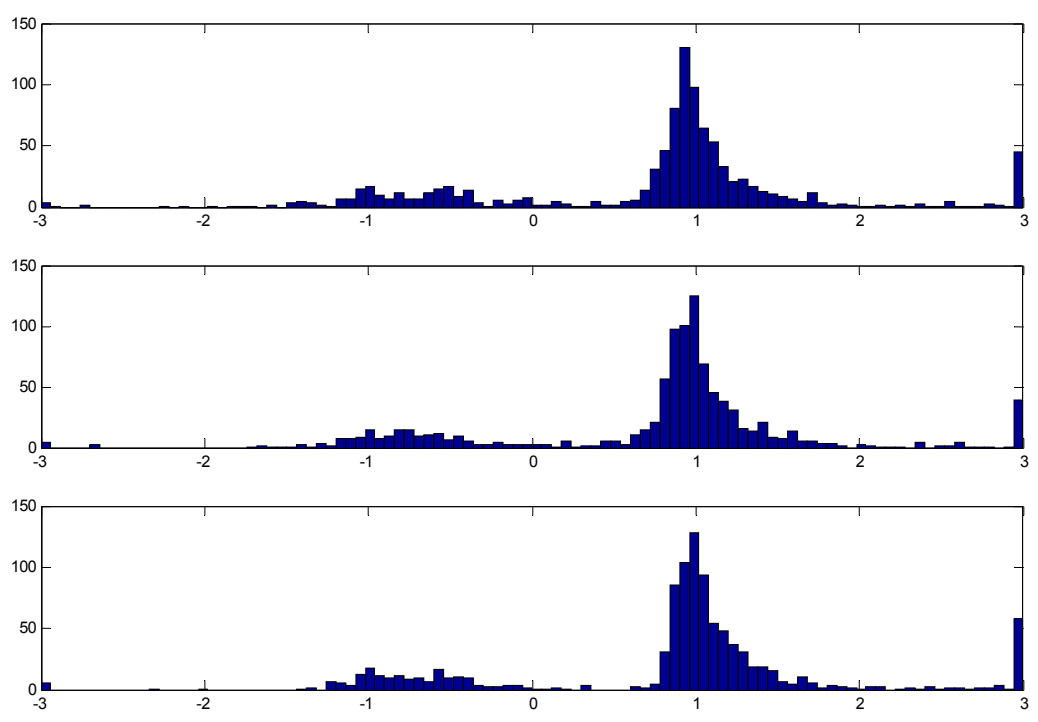

Figure 14: Histograms of $B$ for the baseline model with $\delta$ changed to 0.2. From top to bottom: type I mergers, type II mergers, and type III mergers.
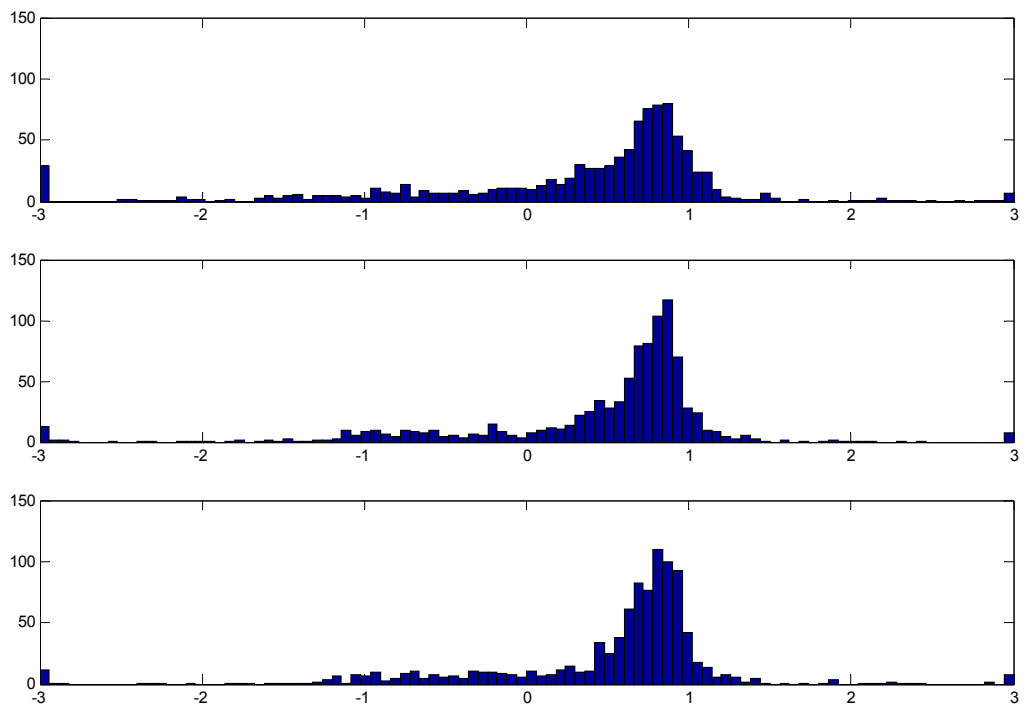

Figure 15: Histograms of $B$ for the baseline model with $\theta$ changed to 0.8 . From top to bottom: type I mergers, type II mergers, and type III mergers. 